Research Article

\title{
New Predictive Equations for Resting Energy Expenditure in Normal to Overweight and Obese Population
}

\author{
Ali M. Almajwal $\mathbb{D}^{1}$ and Mahmoud M. A. Abulmeaty $\mathbb{D}^{1,2}$ \\ ${ }^{1}$ Clinical Nutrition Program, Community Health Sciences Department, King Saud University, Riyadh, Saudi Arabia \\ ${ }^{2}$ Obesity Research and Management Unit, Medical Physiology Department, Faculty of Medicine, Zagazig University, \\ Zagazig, Egypt
}

Correspondence should be addressed to Ali M. Almajwal; aalmajwal123@yahoo.com and Mahmoud M. A. Abulmeaty; dr.abulmeaty@gmail.com

Received 15 February 2019; Revised 12 September 2019; Accepted 3 October 2019; Published 18 December 2019

Academic Editor: Michael Horowitz

Copyright ( 2019 Ali M. Almajwal and Mahmoud M. A. Abulmeaty. This is an open access article distributed under the Creative Commons Attribution License, which permits unrestricted use, distribution, and reproduction in any medium, provided the original work is properly cited.

\begin{abstract}
Background and Aims. The unique demographic and dietary characteristics of modern Arabic population require development of a new predictive equation for the estimation of resting energy expenditure (REE). This study presented new equations characteristic to Saudi population. Methods. A set of predictive equations for REE was derived for 427 healthy male and female subjects (aged 18-57 \pm 14 years). REE was measured (REEm) by indirect calorimetry (IC) and predicted (REEp) using nine equations. REEp was compared with REEm to determine the predictive accuracy of these equations. Using IC and anthropometrics for stepwise linear regression analysis, a new set of equations to predict REE of men and women was developed. Accuracy of the new main equations was further tested in an external sample of 48 subjects (men $=50 \%)$. Results. Using a number of parameters (bias, underprediction, overprediction, and \% accurate prediction), our results suggested that almost all (9/9 in men and 7/9 in women) equations either underpredicted or overpredicted (2/9) REE. None of the already existing equations showed an acceptable REEp/REEm difference as low as $5 \%$ and an accurate prediction $(\sim 55 \%)$ at the individual level. Based on these findings, a new prediction equation (hereafter referred to as the Almajwal-Abulmeaty (AA) equation) was developed using this study's data, after a rigorous stepwise regression analysis using the following formula: $\mathrm{REE}=3832.955+\mathrm{AdjWt}(\mathrm{kg}) \times 48.037-\mathrm{Ht}(\mathrm{cm}) \times 30.642+$ gender $\times 141.268-$ age $($ years $) \times$ 4.525 [AdjWt is Adjusted body weight $=(\mathrm{Wt}-\mathrm{IBW}) / 4+\mathrm{IBW}$. IBW is Ideal body weight; for men $\mathrm{IBW}=(\mathrm{Ht}(\mathrm{cm})-152.4) \times$ $1.0714)+45.36$ and for women $\mathrm{IBW}=(\mathrm{Ht}(\mathrm{cm})-152.4) \times 0.8928)+45.36]$. The regression model accounted for approximately $70 \%$ of the variance in REEm $\left(R^{2}=0.702\right)$. Conclusion. Previous equations likely over- or underpredicted REE. Therefore, the new predictive AA equations developed in this study are recommended for the estimation of REE in young to middle-aged Saudi men and women with different body mass indexes. Future research is also required for further clinical and cross-validation of these new equations.
\end{abstract}

\section{Introduction}

Resting energy expenditure (REE) is the main component of total energy expenditure, taking into consideration the amount of energy the living body requires to maintain its dynamic functions [1]. Indirect calorimetry (IC), a noninvasive method based on the volumes of $\mathrm{O}_{2}$ consumption and $\mathrm{CO}_{2}$ production, is the gold standard for the measurement of REE. However, due to high cost of equipment and operation involved, certain equations have been usually in use to estimate energy expenditure [2-6].
Numerous equations for the prediction of REE have been recommended for general use [7], including the extensively used Harris-Benedict [2] equation, such as Owen et al. [8], Mifflin et al. [9], Bernstein et al. [10], World Health Organization (WHO) [11], Müller et al. [3], and Schofield et al. [12]. However, whether these formulae appropriately calculate REE in subjects living in affluent and modern societies and whether these are valid in population other than those originally investigated in these studies remains unclear. Evidently, major factors contributed to the individual differences of REE, such as gender, age, body 
composition, body size, ethnicity, physical fitness, and hormonal status, and a range of related environmental and genetic factors $[13,14]$. In fact, these prediction formulae have been reported to either over- or underpredict REE in diverse population groups [15].

In addition, the abovementioned predictive equations are considered unsuitable for predicting REE in certain populations with different body mass indexes $[15,16]$. These limitations are partly due to heterogeneity of the reference populations, methodological drawbacks, and also variability of REE [3]. As an example, a recent heterogeneous database of 574 energy expenditure measurements demonstrated an SD of approximately $20 \%$ of the mean values obtained in different genders and age groups [17]. The interindividual coefficient of variation of REE has been reported to be approximately $8-13 \%$ [18], which may lead to a considerably higher number of over- and underestimations of REE using prediction formulae. While Schofield's analysis has been shown to be have played a significant role in reestablishing the importance of using BMR to predict human energy requirements, and some recent, e.g., Müller et al. [3], and old, e.g., Arciero et al. [19], studies have subsequently questioned the universal use and validity of these equations. In addition, other authors [20, 21] have questioned the continued use of equations in the contemporary populations because of the secular variations in their body weight and body composition.

It is worth mentioning that none of the formulae developed to date have taken into account these population differences. Based on studies that report the possible effects of race/ethnicity $[22,23]$ and genetic influences $[13,14]$ on REE, prediction equations developed from a primarily American-European sample might not be fitting for Saudis and may over- or underestimate their energy needs [24, 25]. Consequently, we were of the view that equations that could accurately predict Saudi's REE should be developed. Based on our literature review, REE measurement has not yet been conducted in Saudi Arabia using either IC or predictive equations. This scarcity of data on REE may be due to high costs and sophisticated skills required for IC [3-6] and the absence of Saudi-specific predictive equation to calculate REE. The only studies that have been recently conducted in Saudi Arabia investigated REE in patients [24, 26], female subjects only [25], or male subjects only [27]. In addition, none of these studies focused on developing a new predictive equation specifically for Saudis. Nevertheless, most of them recommended development of a new equation because their results indicated that the Harris-Benedict equation significantly overestimated REE, while the Owen equation significantly underestimated REE, confirming previous reports published by other investigators [25]. Therefore, this study was conducted in an effort to develop predictive equations to calculate REE of normal weight and overweight/obese Saudi population.

\section{Subjects and Methods}

2.1. Participants and Recruitment. The study subjects were recruited from both male and female sections at the Clinical
Nutrition Program, Department of Community Health Science (CHS), Main Plaza of the King Saud University, and the Medical City. Participants (aged 18-57 years) were evaluated between December 2015 and June 2017 in a crosssectional basis. Subjects with diabetes, thyroid disorders, or any other disease that could possibly affect REE were excluded. An additional inclusion requirement was reportedly good health defined as $<1$ sick day/month for the past year and no major existing psychological problems or any other illness [9]. Recruitment was based on the demographic characteristics of the Saudi population, i.e., normal weight, overweight, and obesity (i.e., almost $1: 1: 1$ and as well as $1: 1$ ratio of men and women). In addition, the age range of the sample population (18-57 years) represents the age structure of the Saudi population, i.e., aged 15-64 years represent 72\% of the total population (Saudi demographic survey 2016). Ethics Committee of the College of Applied Medical Sciences (CAMS), King Saud University (KSU), granted ethical approval for this study (Reference no. 11-MED1966-02).

2.2. Procedures. Participants attended an orientation session before the start of the study. All participants completed consent forms and demographics and health-related questionnaires. The participants were evaluated for REE using IC, body composition using bioelectrical impedance analysis (BIA), and anthropometrics to design the REE prediction equation. REE was also estimated using the Harris-Benedict, Ireton-Jones, Carrasco, Mifflin St. Jeor, Kleiber, and Owen equations. Since we were primarily interested in predicting REE across a wide range of body weight, equations developed from samples of exclusively overweight men and women were excluded. Although additional formulae that predict REE based on body composition (e.g., fat-free mass) have previously been developed, the current study was restricted to equations consisting of readily available body measures (e.g., age, weight, and height), as these are clinically more useful and easy to perform.

\subsection{Measures}

2.3.1. Self-Reported Measures. Demographics, smoking status, and reproductive health history were assessed via selfreport [28]. For the purpose of strict compliance, an individual was considered Saudi if she/he was born in Saudi Arabia and reported she/he had at least three grandparents of Saudi heritage.

2.3.2. Anthropometry. Details of anthropometric measurements can be found elsewhere [29]. In brief, a certified physician and a trained dietitian conducted the anthropometric measurements following standard procedures. Height was measured, while the subject stood with legs straight, feet together, shoulders relaxed, arms at sides, and head in the Frankfort horizontal plane, with buttocks, shoulder blades, and heels, and occiput resting against a vertical wall, measured (in cm) using a Seca Model 206 wall stadiometer (Seca Co, Germany). Weight was evaluated using a 
Seca scale with gradations of $0.1 \mathrm{~kg}$. Ideal body weight (IBW) was calculated based on the following equations: for men IBW male $=(\mathrm{Ht}(\mathrm{cm})-152.4) \times 1.0714)+45.36$ and IBW female $=$ $(\mathrm{Ht}(\mathrm{cm})-152.4) \times 0.8928)+45.36$, while Adjusted body weight $($ AdjWt $)=I B W+(W t-I B W) / 4$.

2.3.3. Body Composition. Fat mass (FM) and fat-free mass (FFM) were obtained using TANITA BC-418 analyzer (Tanita Corporation, Japan). As per the manufacturers' specifications, the machine emits an electric current with 50 and $500 \mathrm{kHz}$ in frequency. This multifrequency bioelectric impedance analysis measures components of body impedance, reactance, and resistance that are used to accurately calculate body water, FM, and FFM. Fat mass index (FMI) was calculated by dividing FM (kg) by height $\left(\mathrm{m}^{2}\right)$; FFM index was calculated in the same manner $\left(\mathrm{FFMI}=\mathrm{FFM}(\mathrm{kg}) /\right.$ Height $\left.\left(\mathrm{m}^{2}\right)\right)[29]$.

2.3.4. REE Measurement. To determine REE, IC was performed on all patients using the QUARK RMR (COSMED, Inc., Italy). The laboratory space was maintained at $20-25^{\circ} \mathrm{C}$, ensuring that each individual was physically comfortable and thus properly positioned for measurements. All participants were asked to fast at least for $12 \mathrm{~h}$ and also to abstain from caffeine, nicotine, and physical activity (minimum abstention from vigorous resistance exercise for $24 \mathrm{~h}$ ). Before the test, a $20 \mathrm{~min}$ rest was allocated for device warming and gas, air, and turbine calibration of Quark RMR. Practically speaking, REE is equivalent to RMR.

Energy expenditure was measured for all participants, which took $16 \mathrm{~min}$ for each individual after excluding the first $5 \mathrm{~min}$ preparation/stability time. Laboratory visits were scheduled at the same time of day (between 08:00 and 11:00 $\mathrm{am})$. All the assessments were completed on an outpatient basis, with participants arriving at the laboratory on the morning of testing sessions; silence was observed during session, and subjects comfortably lied in the supine position without moving or sleeping. Sessions that failed to achieve at least 5 min of steady state (variations in the $\mathrm{VO}_{2}$ and $\mathrm{VCO}_{2}$ of $\leq 10 \%$ ) were excluded from the analysis. At any time, it was not accepted to have the \% coefficient of variation in gas volumes $>10 \%$.

2.3.5. REE Calculation. REE was also calculated using equations that included body weight, height, age, sex, FFM, and/or FM. The exclusion criteria for these equations were as follows: equation using age range of $<12$ yrs or only elderly; those using only one sex, those having normal weight based on Cole et al. [30] (not applicable to large databases of Schofield and Harris and Benedict), those with insufficient information, those considering only a specific ethnic group (other than white), based on small sample size $(n<50)$; impractical or suspected body composition as a variable, glucose concentrations, or diabetes as a variable, total energy expenditure, athletes, and duplicate publications.

For each subject, the REE was predicted in $\mathrm{kcal} /$ day by using the selected equations and then compared with measured REE. The actual body weight during IC measurement was used for this calculation. Demographic and anthropometric data were used to calculate REE using predictive equations developed by Harris and Benedict [2], Harris and Benedict equation reevaluated by Roza et al. [31], Bernstein et al. [10], Owen et al. [8], Mifflin et al. [9], Schofield (weight only), Schofield (both weight and height) [12], FAO/WHO/UNU (weight only), and FAO/WHO/UNU (both weight and height) [11] (Table 1).

2.4. External Validation. A total of 48 subjects $(\operatorname{men}=50 \%)$ were used for external validation of the main new equations. The validation population was recruited from visitors of therapeutic nutrition clinic at CAMS, KSU. The same inclusion criteria were applied, and the same measures were recorded as the original study population.

2.5. Statistical Analysis. All the data were analyzed using SPSS (version 23; SPSS Inc., Chicago, IL, USA). Continuous variables were expressed as means (SD), and dichotomous variables were expressed as percentages and frequencies. The accuracy of predictive formulae at the individual level was defined as percentage of the subjects whose predicted RMR was within $\pm 10 \%$ of the measured RMR $[32,33]$. The degree of agreement between the measured and predicted REE was evaluated using Bland-Altman limits during the agreement analyses. Limits of agreement were defined as the mean difference $\pm 2.0 \mathrm{SD}$. The estimated accuracy was defined as "the percentage of the subjects whose REEp was within $\pm 10 \%$ of REEm." Under- and overestimation were defined as $<10 \%$ and $>10 \%$ of REEm, respectively [34]. Predictive equations were developed and compared with commonly used equations for validation $[9,33]$. The method suggested by Bland and Altman [35] was used to plot the agreement between (a) IC and Harris and Benedict equation (1919 and 1984), (b) IC and Bernstein equation, (c) IC and Owen equation, (d) IC and Mifflin equation, (e) IC and Schofield equation, and (f) IC and WHO equation, in addition to IC and the main two new equations (AA_1 and AA_FFM). The Bland-Altman method gives calculation for mean difference between two measurement methods (the bias) and 95\% limits of agreement as the mean difference $( \pm 1.96 \mathrm{SD})$. The values are expressed as absolute (kcal) and percentage (\%). We used multiple stepwise regression analysis to derive the new prediction equation (hereafter designated as "Almajwal-Abulmeaty" (AA equation)) to estimate REE based on age, gender, weight, and height as independent variables $[9,32-34]$. We calculated Pearson's coefficient of determination $\left(R^{2}\right)$ and residual standard deviation (RD) as goodness-of-fit measures between the predicted and measured regression equations used.

\section{Results}

3.1. Baseline Characteristics of the Participants. Among 510 participants, the inclusion criteria were eligible for 423 participants (men 49\%) (Figure 1). Table 2 shows the characteristics of the 423 Saudi men and women, with a mean BMI of $28.5 \pm 6.1 \mathrm{~kg} / \mathrm{m}^{2}$. All anthropometric and body composition parameters significantly differed between men and women and between the three BMI groups, except for height $(P$, for all trends $<0.05)$. 
TABLe 1: Published predictive equations selected and used for the current study.

\begin{tabular}{|c|c|c|}
\hline Equation name & $\begin{array}{l}\text { Abbreviated/rephrased } \\
\text { in this paper }\end{array}$ & Full equation \\
\hline Harris and Benedict [2] & H-B ${ }^{1919}$ & $\begin{array}{l}\text { M: WT } \times 13.7516+\mathrm{HTCM} \times 5.0033-\text { age } \times 6.755+66.473=\mathrm{kcal} / \mathrm{d} \\
\text { F: WT } \times 9.5634+\mathrm{HTCM} \times 1.8496-\text { age } \times 4.6756+655.0955=\mathrm{kcal} / \mathrm{d}\end{array}$ \\
\hline Harris and Benedict [31] & $\mathrm{H}-\mathrm{B}^{1984}$ & $\begin{array}{l}\text { Harris and Benedict equation reevaluated by Roza et al. } \\
\text { M: } 13.397 \times \mathrm{WT}+4.799 \times \mathrm{HTCM}-5.677 \times \text { age }+88.362 \\
\text { F: } 9.247 \times \mathrm{WT}+3.098 \times \mathrm{HTCM}-4.33 \times \text { age }+477.593\end{array}$ \\
\hline Bernstein et al. [10] & Bernstein & $\begin{array}{l}\text { M: } 11.02 \times \mathrm{WT}+10.23 \times \mathrm{HTCM}-5.8 \times \text { age }-1032=\mathrm{kcal} / \mathrm{d} \\
\text { F: } 7.48 \times \mathrm{WT}-0.42 \times \mathrm{HTCM}-3 \times \text { age }+844=\mathrm{kcal} / \mathrm{d}\end{array}$ \\
\hline Owen et al. [8] & Owen & $\begin{array}{c}\text { M: WT } \times 10.2+879=\mathrm{kcal} / \mathrm{d} \\
\mathrm{F}: \mathrm{WT} \times 7.18+795=\mathrm{kcal} / \mathrm{d}\end{array}$ \\
\hline Mifflin et al. [9] & Mifflin & $9.99 \times \mathrm{WT}+6.25 \times \mathrm{HTCM}-4.92 \times$ age $+166 \times$ gender $-161=\mathrm{kcal} / \mathrm{d}$ \\
\hline Schofield [12] & Schofield ${ }^{\mathrm{W}}$ & $\begin{array}{c}\text { Equations using weight only } \\
\text { M: } 30-60 \text { y: } 0.048 \times \mathrm{WT}+3.653=\mathrm{MJ} / \mathrm{d} \\
M \geq 60 \text { y: } 0.049 \times \mathrm{WT}+2.459=\mathrm{MJ} / \mathrm{d} \\
\mathrm{F}: 30-60 \text { y: } 0.034 \times \mathrm{WT}+3.538=\mathrm{MJ} / \mathrm{d} \\
F \geq 60 \text { y: } 0.038 \times \mathrm{WT}+2.755=\mathrm{MJ} / \mathrm{d}\end{array}$ \\
\hline Schofield [12] & Schofield ${ }^{\mathrm{WH}}$ & $\begin{array}{c}\text { Equations using weight and height } \\
\text { M: } 30-60 \text { y: } 0.048 \times \mathrm{WT}-0.011 \times \mathrm{HTM}+3.67=\mathrm{MJ} / \mathrm{d} \\
M \geq 60 \text { y: } 0.038 \times \mathrm{WT}+4.068 \times \mathrm{HTM}-3.491=\mathrm{MJ} / \mathrm{d} \\
\mathrm{F}: 30-60 \text { y: } 0.034 \times \mathrm{WT}+0.006 \times \mathrm{HTM}+3.53=\mathrm{MJ} / \mathrm{d} \\
F \geq 60 \text { y: } 0.033 \times \mathrm{WT}+1.917 \times \mathrm{HTM}+0.074=\mathrm{MJ} / \mathrm{d}\end{array}$ \\
\hline FAO/WHO/UNU [11] & $\mathrm{WHO}^{\mathrm{W}}$ & $\begin{array}{c}\text { Equations using weight only } \\
\mathrm{M}: 30-60 \mathrm{y}: 11.6 \times \mathrm{WT}+879=\mathrm{kcal} / \mathrm{d} \\
M \geq 60 \mathrm{y}: 13.5 \times \mathrm{WT}+487=\mathrm{kcal} / \mathrm{d} \\
\mathrm{F}: 30-60 \mathrm{y}: 8.7 \times \mathrm{WT}+829=\mathrm{kcal} / \mathrm{d} \\
F \geq 60 \mathrm{y}: 10.5 \times \mathrm{WT}+596=\mathrm{kcal} / \mathrm{d}\end{array}$ \\
\hline FAO/WHO/UNU [11] & $\mathrm{WHO}^{\mathrm{W}}$ & $\begin{array}{c}\text { Equations using weight and height } \\
\text { M: } 30-60 \text { y: } 11.3 \times \mathrm{WT}-16 \times \mathrm{HTM}+901=\mathrm{kcal} / \mathrm{d} \\
M \geq 60 \text { y: } 8.8 \times \mathrm{WT}+1128 \times \mathrm{HTM}-1071=\mathrm{kcal} / \mathrm{d} \\
\mathrm{F}: 30-60 \text { y: } 8.7 \times \mathrm{WT}-25 \times \mathrm{HTM}+865=\mathrm{kcal} / \mathrm{d} \\
F \geq 60 \text { y: } 9.2 \times \mathrm{WT}+637 \times \mathrm{HTM}-302=\mathrm{kcal} / \mathrm{d}\end{array}$ \\
\hline
\end{tabular}

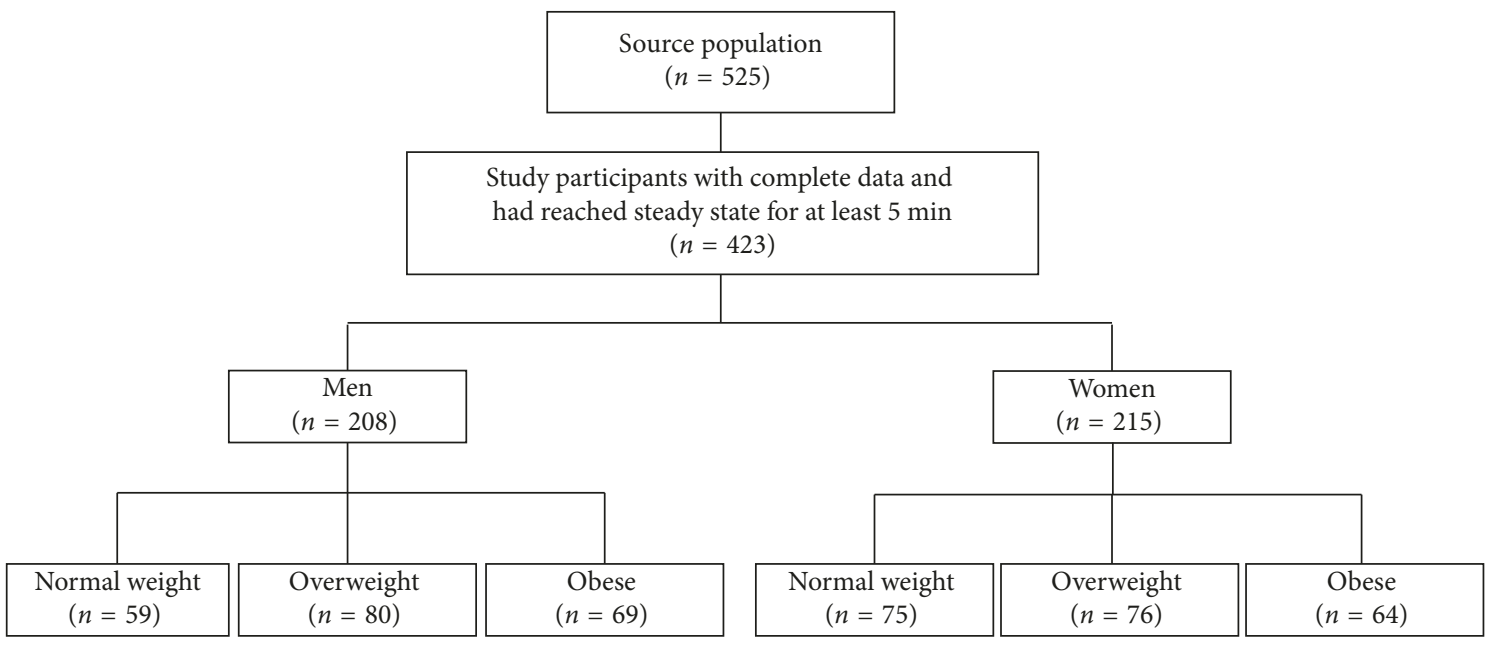

Figure 1: STROBE flowchart of the study participants.

3.2. Agreement between Measured and Predicted REE (REEm and REEP). We evaluated differences in the following measures: bias (difference between REEp and REEm) (kcal/ day), percent bias (REEm - REEp by equations multiplied 100/REEp by equations), underestimation (percentage of all subjects whose REEp was $<90 \%$ of REEm), overestimation (percentage of all subjects whose REEp was $>110 \%$ of the measured REEm), and accurate prediction (percentage of all subjects whose REEp was within $90 \%$ to $110 \%$ of REEm). 


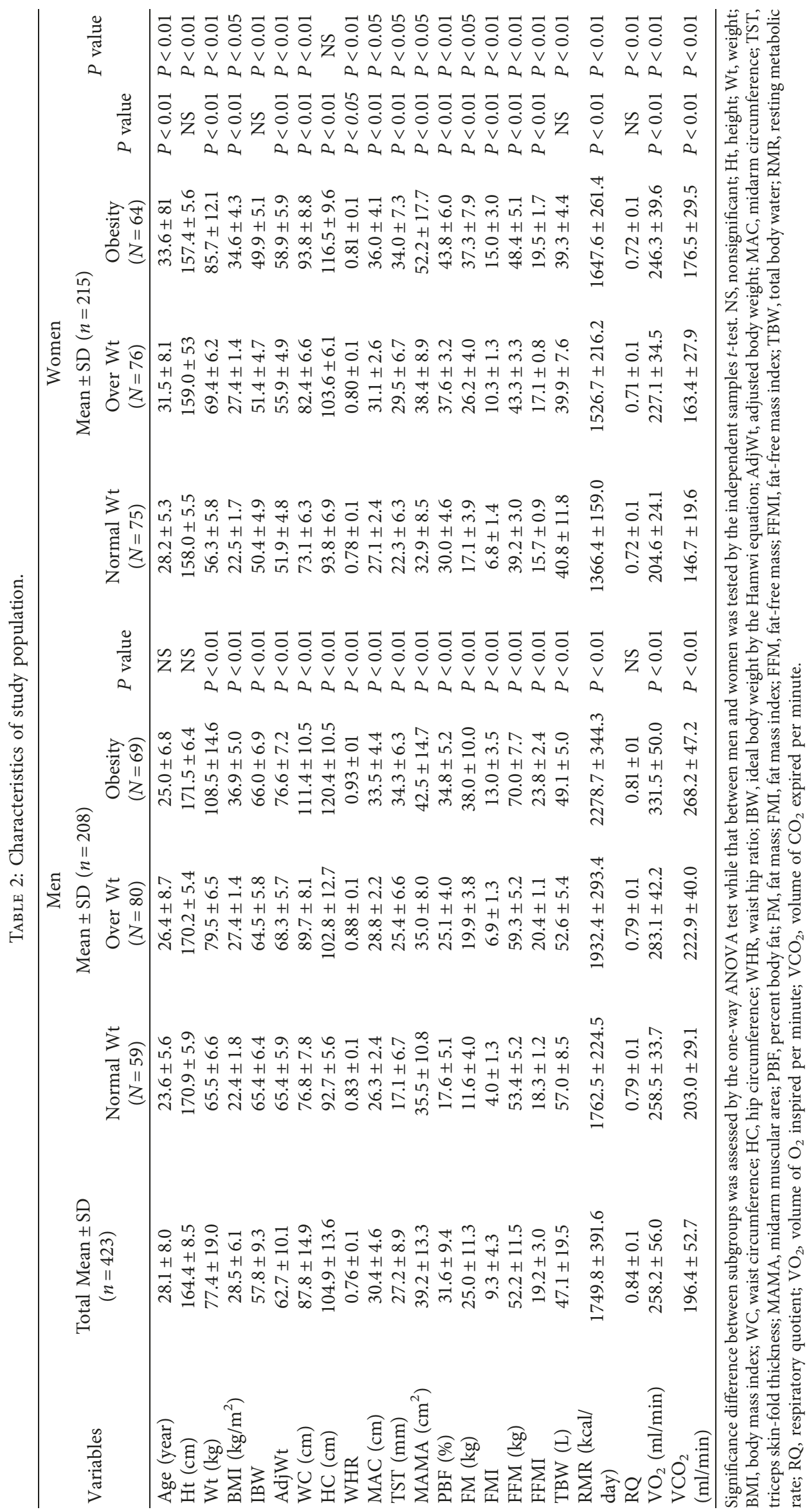


Table 3 shows RMR (kcal/day), bias ( $\mathrm{kcal}$ and \%), maximum values found for positive error (overprediction) and negative error (underprediction), percentage accurate predictions, and percentage under- and overpredictions. In men, REEp by all 10 predictive equations was lower than REEm, the lowest being by the Bernstein equation (491.0 kcal/day), followed by Owen (251 kcal/day), Mifflin (199 kcal/day), H-B ${ }^{1919}$ (92.8 kcal/day), $\mathrm{HB}^{1984}$ (76.8 kcal/day), Schofield (Wt, Ht) (28.2 kcal/day), Schofield (Wt) (24.7 kcal/day), WHO (Wt) $(17.2 \mathrm{kcal} /$ day), and $\mathrm{WHO}(\mathrm{Wt}, \mathrm{Ht})(16.8 \mathrm{kcal} /$ day $)$. The number of underpredictions within $\pm 10 \%$ range varied from $90.4 \%$ (Bernstein equation) to $20.2 \%$ (WHO ${ }^{\mathrm{W}}$ equation) in men and from $82.3 \%$ (Bernstein equation) to $17.2 \%$ (each Schofield ${ }^{\mathrm{W}}$ and $\mathrm{WHO}^{\mathrm{W}}$ equations) in women. The number of overpredictions within $\pm 10 \%$ range varied from $23.6 \%$ ( $\mathrm{WHO}^{\mathrm{W}}$ equation) to $0 \%$ (Bernstein equation) in men and from $27.4 \%\left(\mathrm{WHO}^{\mathrm{W}}\right.$ equation) to $0.5 \%$ (Bernstein equations) in women.

The percentage of accurate prediction varied greatly for all 10 predictive equations. The equations with the highest percentage accurate predictions $(>55 \%)$ were $\mathrm{WHO}^{\mathrm{WH}}, \mathrm{WHO}^{\mathrm{W}}$, Schofield $^{\mathrm{WH}}$, and Schofield ${ }^{\mathrm{W}}$ equations, respectively, having $\%$ accurate prediction of $56.3,56.3,56.3$, and 55.8 , followed by the equations of $\mathrm{H}_{-} \mathrm{B}^{1919}$ (55.3\%), $\mathrm{H}-\mathrm{B}^{1984}$ (54.8\%), Mifflin (44.2\%), Owen (37.0\%), and Bernstein (9.6\%). In women, out of 10 equations, two $\left(\mathrm{WHO}^{\mathrm{W}}\right.$, Schofield ${ }^{\mathrm{W}}$ ) overestimated REE (mean REEp $>$ REEm) although the difference between the means was not significant $(P>0.05)$. The remaining eight equations underestimated REE (REEp $<$ REEm) with a statistically significant difference ( $P$ for all trends, <0.05). Contrary to men, equations of $\mathrm{H}-\mathrm{B}^{1984}$ for female participants had the highest accurate prediction (62.3\%), followed by $\mathrm{H}_{-} \mathrm{B}^{1919}(61.4 \%), \mathrm{WHO}^{\mathrm{WH}}$ (58.6\%), Schofield ${ }^{\mathrm{WH}},(58.6 \%)$, Schofield $^{\mathrm{W}}$ (55.8\%), Mifflin (52.6\%), Owen (37.7\%), and Bernstein (17.2\%). All the prediction equations used in the current study significantly underestimated the measured $\operatorname{REE}(P$ rends for all $<0.001)$ in men (Table 3 ).

3.3. Bland-Altman Plots. Figures 2 and 3 show the Bland-Altman plots comparing REE measurements obtained by IC (REEm) and by prediction equations (REEp) in men and women, respectively. REEm and REEp were significantly different. In men and women, the Bernstein equation revealed the highest underprediction $(491.0 \pm 250.0 \mathrm{kcal} / \mathrm{day}$; bias of $33.5 \%$ and $301.3 \pm 186.9 \mathrm{kcal} /$ day; and bias of $24.7 \%$, respectively). In contrast, the WHO (Wt, HT), WHO (Wt), Schofield (WT, HT), and Schofield $(\mathrm{Wt})$ were the most accurate compared to IC in men, whereas HB (1984), HB (1919), Schofield (Wt), and Mifflin were the most accurate equations in women.

\subsection{Development of the New REE Prediction Equations.} When combining both men and women, REE significantly correlated with age $(r=-0.230, P=0.01)$, height $(r=0.614$, $P<0.001)$, weight $(r=0.730, \quad P<0.001)$, and gender $(r=0.432, P<0.001)$. Table 4 presents all the values of this correlation matrix. Other parameters (i.e., BMI, FFM, and FM) were also strongly correlated. However, adding any additional parameter had no significant effect on the regression model. For example, we excluded BMI from the final regression model because calculating the BMI will add another step in the clinical setting. Thus, age, height, and weight were retained in the final regression model as these are the parameters that can be easily measured in both population analysis and in clinical settings [9]. Each of the variables included in the equation significantly and independently contributed to the model $(P$, for all trends $<0.01)$. Of no surprise, the best REE predictor was body weight $(r=0.730)$. Of the remaining variables, height demonstrated the next strongest relationship to REE ( $r=0.614 ; P<0.01)$, followed by gender $(r=0.432, P<0.001)$ and age $(r=-0.230 ; P<0.01)$. The results of the multiple regression analysis produced the equations in predicting REE (kcal/day), as shown in the multivariate analysis of all study population, and the variables included in the equations significantly and independently contributed to the model $(P=0.001)$. Stepwise entry of anthropometric variables revealed that adjusted weight, height, gender, and age increases $R^{2}$ of this model from 0.620 to 0.702 , as shown in Table 5, equation 1 . Other body composition variables (TBW, FFM, and FM) that were considered in the analyses increased $R^{2}$ to 0.706 , but for clinical ease and slight increase in $R^{2}$, the much simpler equation 1 was considered. After dividing the sample into normal weight and overweight/ obese categories, another set of equations were created but $R^{2}<0.7$ (Table 5). Separate use of stepwise multiple regression analysis for male or female subjects created equations with $R^{2}<0.54$ (Tables 6 and 7).

3.5. Validation of the New Equations. Table 8 represents the general characteristics of the study population used for testing the accuracy of the new equations. As shown in Table 9, the new AA_1 and AA_FFM equations showed a lower bias and \% of bias, as well as a higher accurate estimation and correlation with results of IC than Mifflin, Owen, and Bernstein equations. There was a significant difference between the means of measures by IC and estimations by Mifflin, $(P<0.001 ; 95 \% \mathrm{CI}=73.05$ to 206.31$)$, Owen $(P<0.001 ; 95 \% \mathrm{CI}=134.49$ to 264.70$)$, and Bernstein equations $(P<0.001 ; 95 \% \quad \mathrm{CI}=303.25$ to 447.64$)$. The Bland-Altman plot (Figure 4 ) showed the agreement between the IC measurements and the new equations.

\section{Discussion}

This study compared the accuracy of nine predictive equations. Therefore, REEm was compared with REEp in a sample composing Saudi men and women. This study revealed that the widely used REE prediction equations used in this study cannot be used for a population living in an affluent and modern society in Saudi Arabia. In this study, we found significant and systematic over- and underpredictions between the predicted and measured REE values.

The percentage accurate predictions varied between equations, from $56.3 \%$ (for each $\mathrm{WHO}^{\mathrm{WH}}, \mathrm{WHO}^{\mathrm{H}}$, and Schofield ${ }^{\mathrm{WH}}$ ) to $9.6 \%$ (Bernstein) in men and from $62.3 \%$ $\left(\mathrm{HB}^{1984}\right)$ to $17.2 \%$ (Bernstein) in women. The bias for predictive equations used in this study varied from $33.5 \%$ 
TABLE 3: Accuracy of the resting metabolic rate measured by indirect calorimetry and that calculated by some predictive equations.

\begin{tabular}{|c|c|c|c|c|c|c|c|}
\hline Tools & $\begin{array}{c}\text { RMR (kcal/ } \\
\text { day) }\end{array}$ & Bias (kcal) & $\begin{array}{c}\text { Percent of bias } \\
(\%)\end{array}$ & $\begin{array}{c}\text { Underestimation } \\
(\%)\end{array}$ & $\begin{array}{c}\text { Overestimation } \\
(\%)\end{array}$ & $\begin{array}{c}\text { Accurate estimation } \\
(\%)\end{array}$ & $r$ \\
\hline \multicolumn{8}{|l|}{$\operatorname{Men}(n=208)$} \\
\hline Quark RMR & $1999.1 \pm 360.1$ & - & - & - & - & - & - \\
\hline $\mathrm{HB}^{1919}$ & $1922.3 \pm 288.5^{*}$ & $76.8 \pm 251.2$ & $4.3 \pm 13.4$ & 26.9 & 17.8 & 55.3 & 0.721 \\
\hline $\mathrm{HB}^{1984}$ & $1906.2 \pm 280.0^{*}$ & $92.8 \pm 249.9$ & $5.3 \pm 13.4$ & 30.3 & 14.9 & 54.8 & 0.722 \\
\hline Bernstein & $1508.1 \pm 246.8^{*}$ & $491.0 \pm 250.0$ & $33.5 \pm 17.6$ & 90.4 & 0 & 9.6 & 0.720 \\
\hline Owen & $1747.6 \pm 204.9^{*}$ & $251.5 \pm 257.5$ & $14.3 \pm 14.6$ & 59.1 & 3.8 & 37.0 & 0.714 \\
\hline Mifflin & $1799.6 \pm 215.5^{*}$ & $199.5 \pm 252.8$ & $11.0 \pm 14.0$ & 50.5 & 5.3 & 44.2 & 0.723 \\
\hline Schofield (Wt) & $1973.6 \pm 302.1$ & $24.7 \pm 256.3$ & $1.9 \pm 13.3$ & 21.6 & 22.6 & 55.8 & 0.714 \\
\hline $\begin{array}{l}\text { Schofield (Wt, } \\
\mathrm{Ht} \text { ) }\end{array}$ & $1970.9 \pm 302.3$ & $28.2 \pm 256.3$ & $1.8 \pm 13.3$ & 21.1 & 21.6 & 56.3 & 0.714 \\
\hline WHO (Wt) & $1981.9 \pm 307.4$ & $17.18 \pm 257.2$ & $1.3 \pm 13.2$ & 20.2 & 23.6 & 56.3 & 0.714 \\
\hline WHO (Wt, Ht) & $1982.3 \pm 309.0$ & $16.8 \pm 257.7$ & $1.3 \pm 13.3$ & 20.7 & 23.1 & 56.3 & 0.713 \\
\hline \multicolumn{8}{|l|}{ Women $(n=215)$} \\
\hline Quark RMR & $1508.6 \pm 241.3$ & - & - & - & - & - & - \\
\hline $\mathrm{HB}^{1919}$ & $1470.9 \pm 134.3^{*}$ & $37.7 \pm 178.1$ & $2.4 \pm 11.9$ & 20.5 & 18.1 & 61.4 & 0.687 \\
\hline $\mathrm{HB}^{1984}$ & $1479.5 \pm 132.9^{*}$ & $29.2 \pm 178.5$ & $1.8 \pm 11.8$ & 19.5 & 18.1 & 62.3 & 0.687 \\
\hline Bernstein & $1207.3 \pm 102.1^{*}$ & $301.3 \pm 186.9$ & $24.7 \pm 14.7$ & 82.3 & 0.5 & 17.2 & 0.684 \\
\hline Owen & $1296.8 \pm 103.7^{*}$ & $211.9 \pm 189.2$ & $16.1 \pm 14.0$ & 60.9 & 1.4 & 37.7 & 0.663 \\
\hline Mifflin & $1372.9 \pm 150.8^{*}$ & $135.7 \pm 177.4$ & $9.9 \pm 12.7$ & 41.9 & 5.6 & 52.6 & 0.680 \\
\hline Schofield (Wt) & $1522.2 \pm 214.0$ & $-13.6 \pm 188.5$ & $-0.4 \pm 12.3$ & 17.2 & 27.0 & 55.8 & 0.663 \\
\hline $\begin{array}{l}\text { Schofield (Wt, } \\
\mathrm{Ht} \text { ) }\end{array}$ & $1484.2 \pm 201.7$ & $24.5 \pm 184.5$ & $2.1 \pm 12.4$ & 22.8 & 18.6 & 58.6 & 0.666 \\
\hline WHO (Wt) & $1523.3 \pm 212.3$ & $-14.7 \pm 188.0$ & $-0.5 \pm 12.3$ & 17.2 & 27.4 & 55.3 & 0.663 \\
\hline WHO (Wt, Ht) & $1492.6 \pm 198.3$ & $16.0 \pm 183.8$ & $1.4 \pm 12.3$ & 20.5 & 20.9 & 58.6 & 0.666 \\
\hline
\end{tabular}

Bias $=$ RMR measured by Quark RMR-REE predicted by equations. Percent of bias $=(($ RMR measured by Quark RMR-REE predicted by equations $) \times 100) /$ REE predicted by equations. Accurate estimation = percentage of all subjects whose REE was within $90 \%$ to $110 \%$ of measured RMR by Quark RMR. Underestimation = percentage of all subjects whose REE was less than $90 \%$ of measured RMR by Quark RMR. Overestimation $=$ percentage of all subjects whose REE was more than 110\% of measured RMR by Quark RMR. $r=$ Pearson's correlation coefficient between RMR measured by Quark RMR and REE predicted by equations. * significant difference vs the measured RMR (Quark RMR) $(P \leq 0.05)$.

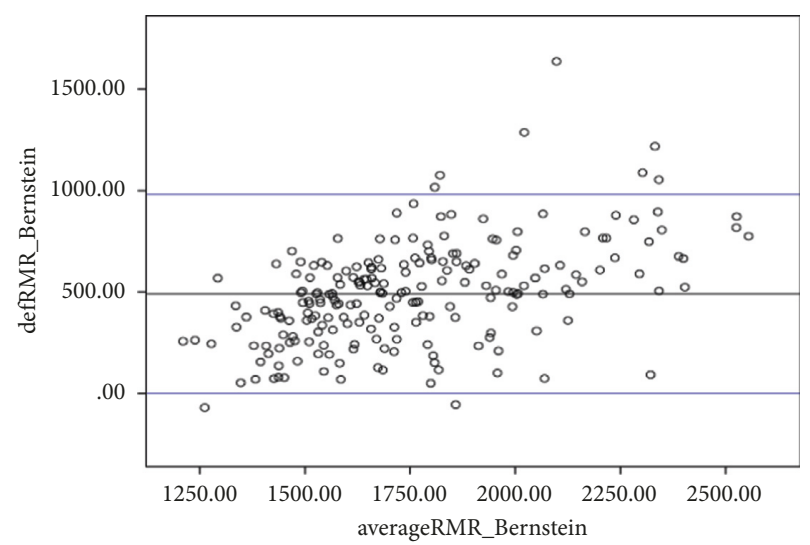

(a)

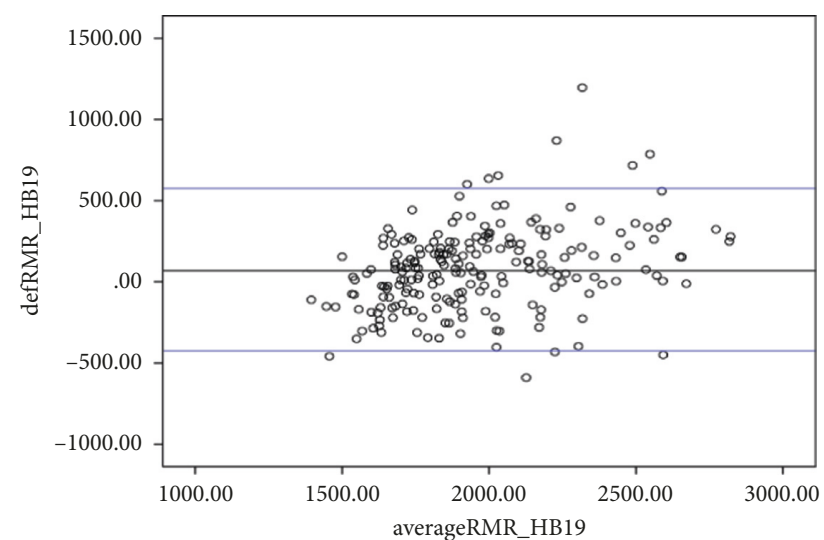

(b)

Figure 2: Continued. 


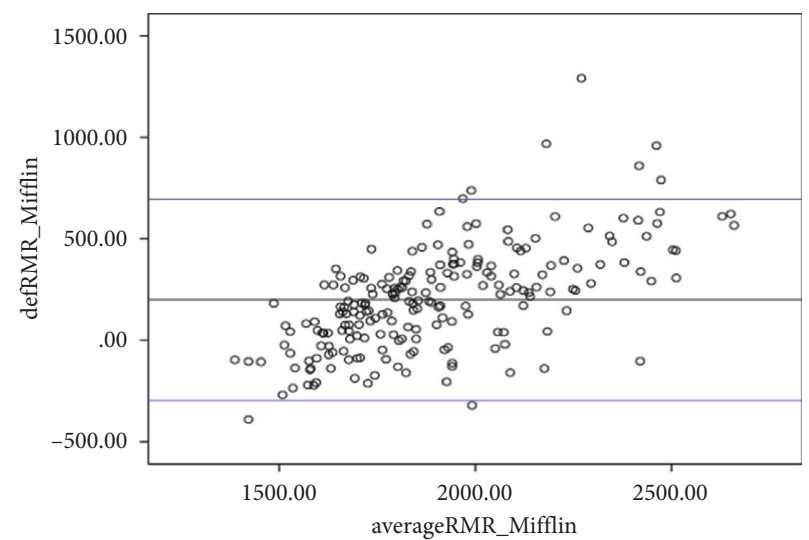

(c)

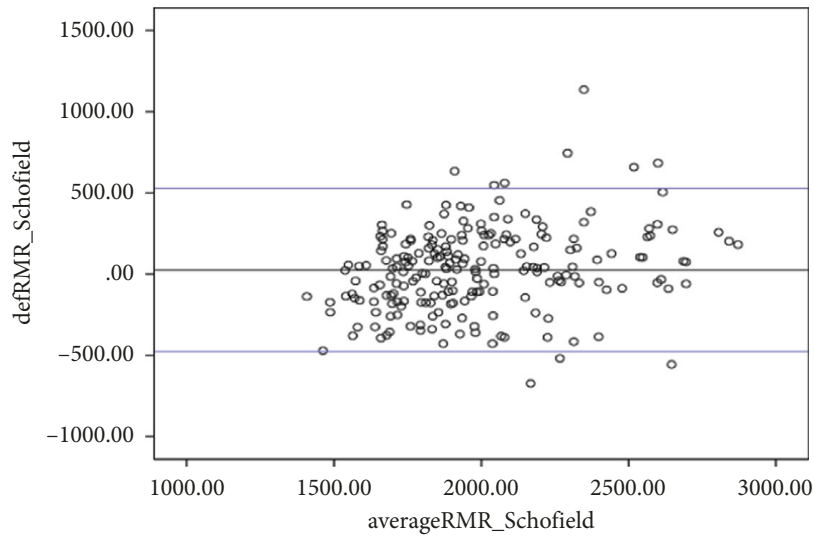

(e)

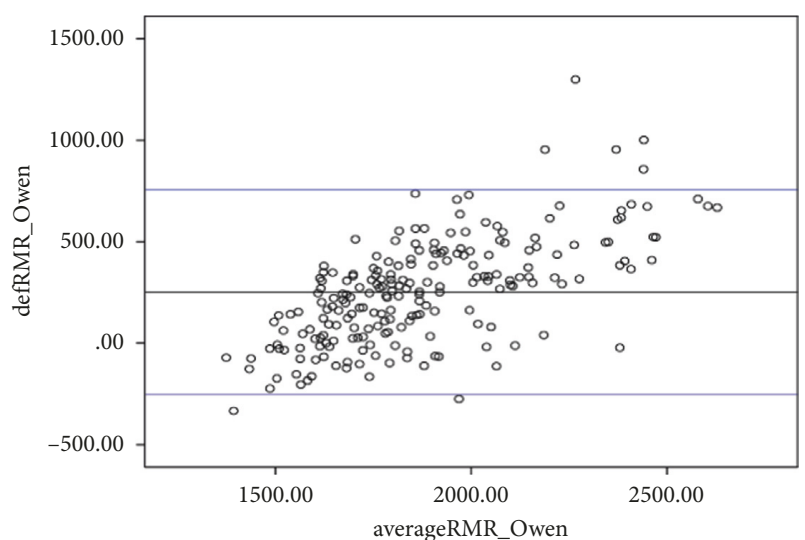

(d)

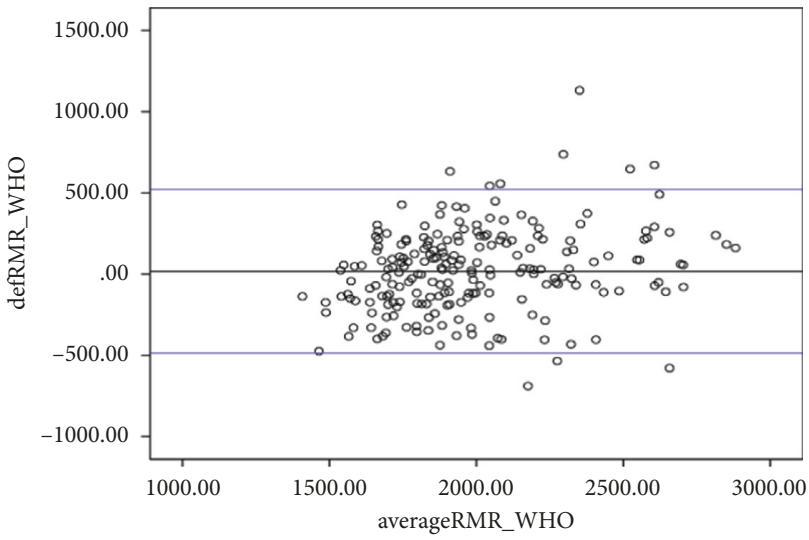

(f)

FIGURE 2: Bland-Altman plots comparing indirect calorimetry (IC) and the following prediction equations for the basal metabolic rate in Saudi men: (a) Bernstein; (b) HB; (c) Mifflin; (d) Owen; (e) Schofield (Wt only); (f) WHO (Wt only).

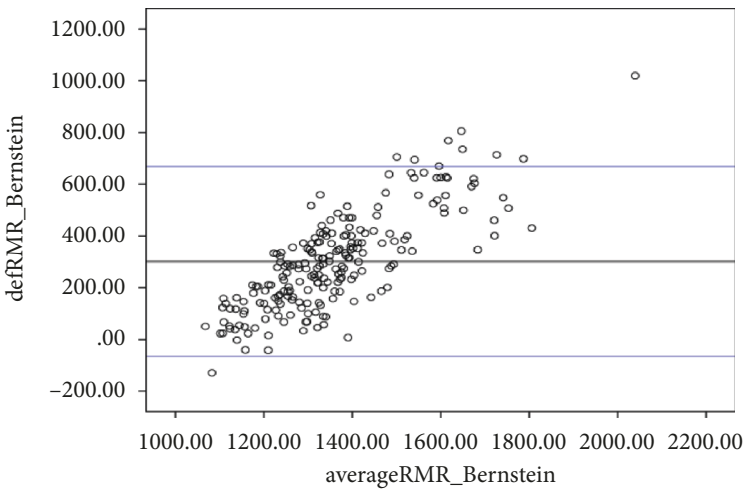

(a)

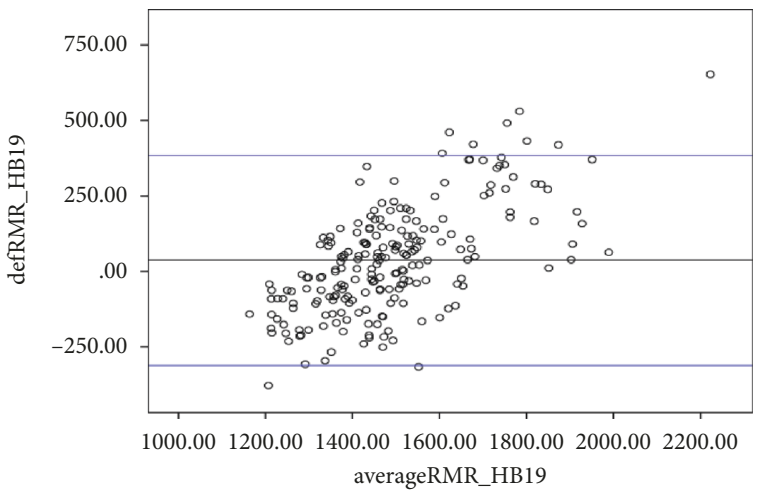

(b)

FIgUre 3: Continued. 


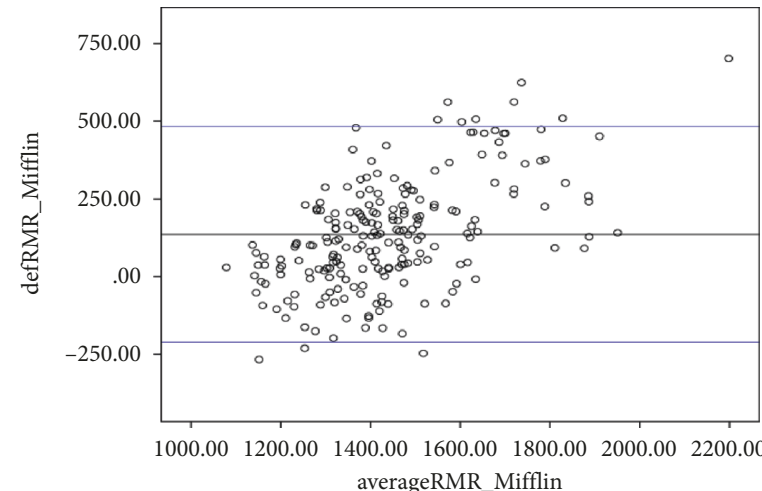

(c)

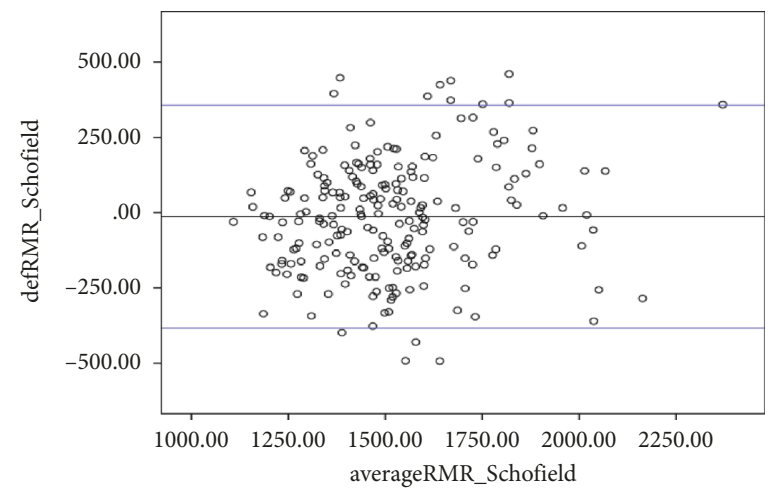

(e)

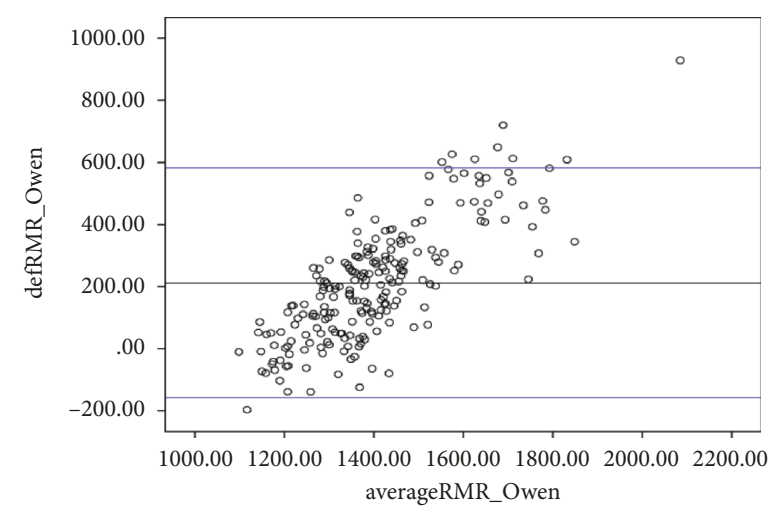

(d)

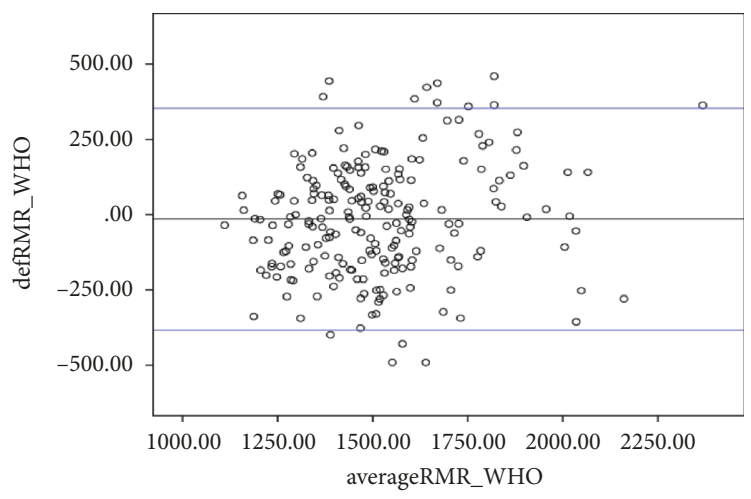

(f)

FIGURE 3: Bland-Altman plots comparing indirect calorimetry (IC) and the following prediction equations for the basal metabolic rate in Saudi women: (a) Bernstein; (b) HB; (c) Mifflin; (d) Owen; (e) Schofield (Wt only); (f) WHO (Wt only).

TABLE 4: Pearson correlation coefficients for resting metabolic rate (RMR) and other predictive variables.

\begin{tabular}{|c|c|c|c|c|c|c|c|c|c|}
\hline \multirow[b]{2}{*}{$\begin{array}{l}\text { Independent } \\
\text { variables }\end{array}$} & \multirow[b]{2}{*}{$\begin{array}{c}\text { Total } \\
(n=423)\end{array}$} & \multicolumn{4}{|c|}{ Men } & \multicolumn{4}{|c|}{ Women } \\
\hline & & $\begin{array}{l}\text { Total men } \\
(N=208)\end{array}$ & $\begin{array}{c}\text { Normal Wt } \\
\quad(N=59)\end{array}$ & $\begin{array}{c}\text { Over Wt } \\
(N=80)\end{array}$ & $\begin{array}{l}\text { Obesity } \\
(N=69)\end{array}$ & $\begin{array}{c}\text { Total women } \\
(N=215)\end{array}$ & $\begin{array}{c}\text { Normal Wt } \\
\quad(N=75)\end{array}$ & $\begin{array}{c}\text { Over Wt } \\
(N=76)\end{array}$ & $\begin{array}{l}\text { Obesity } \\
(N=64)\end{array}$ \\
\hline Age & $-0.230^{* *}$ & -0.039 & 0.038 & -0.072 & -0.141 & 0.053 & -0.120 & -0.142 & -0.055 \\
\hline $\mathrm{Ht}$ & $0.614^{* *}$ & $0.299^{* *}$ & $0.477^{* *}$ & $0.238^{*}$ & $0.335^{* *}$ & $0.263^{* *}$ & $0.418^{* *}$ & $0.405^{* *}$ & 0.173 \\
\hline $\mathrm{Wt}$ & $0.750^{* *}$ & $0.714^{* *}$ & $0.352^{* *}$ & $0.378^{* *}$ & $0.659^{* *}$ & $0.663^{* *}$ & $0.348^{* *}$ & $0.465^{* *}$ & $0.694^{* *}$ \\
\hline BMI & $0.553^{* *}$ & $0.647^{* *}$ & 0.026 & $0.290^{* *}$ & $0.487^{* *}$ & $0.603^{* *}$ & 0.085 & $0.272^{*}$ & $0.686^{* *}$ \\
\hline IBW & $0.633^{* *}$ & $0.299^{* *}$ & $0.477^{* *}$ & $0.237^{*}$ & $0.335^{* *}$ & $0.263^{* *}$ & $0.418^{* *}$ & $0.405^{* *}$ & 0.173 \\
\hline AdjWt & $0.787^{* *}$ & $0.643^{* *}$ & $0.485^{* *}$ & $0.288^{* *}$ & $0.579^{* *}$ & $0.571^{* *}$ & $0.426^{* *}$ & $0.441^{* *}$ & $0.469^{* *}$ \\
\hline WC & $0.667^{* *}$ & $0.642^{* *}$ & 0.144 & 0.219 & $0.535^{* *}$ & $0.538^{* *}$ & 0.037 & $0.240^{*}$ & $0.531^{* *}$ \\
\hline $\mathrm{HC}$ & $0.508^{* *}$ & $0.629^{* *}$ & $0.347^{* *}$ & 0.209 & $0.585^{* *}$ & $0.556^{* *}$ & $0.284^{*}$ & 0.149 & $0.520^{* *}$ \\
\hline WHR & $0.394^{* *}$ & $0.155^{*}$ & -0.094 & -0.105 & -0.007 & 0.112 & $-0.244^{*}$ & 0.155 & 0.122 \\
\hline MAC & $0.314^{* *}$ & $0.603^{* *}$ & 0.193 & $0.351^{* *}$ & $0.414^{* *}$ & $0.502^{* *}$ & -0.028 & 0.221 & $0.407^{* * * *}$ \\
\hline TST & $0.243^{* *}$ & $0.486^{* *}$ & -0.036 & 0.081 & $0.298^{*}$ & $0.325^{* *}$ & $-0.233^{*}$ & 0.081 & $0.249^{*}$ \\
\hline MAMA & $0.208^{* *}$ & $0.358^{* *}$ & 0.155 & $0.271^{*}$ & $0.312^{* *}$ & $0.397^{* *}$ & 0.138 & 0.150 & $0.267^{*}$ \\
\hline $\mathrm{PBF}$ & -0.038 & $0.521^{* *}$ & -0.014 & -0.061 & $0.298^{*}$ & $0.458^{* *}$ & 0.201 & 0.100 & 0.197 \\
\hline FM & $0.415^{* *}$ & $0.641^{* *}$ & 0.107 & 0.089 & $0.524^{* *}$ & $0.629^{* *}$ & $0.280^{*}$ & $0.336^{* *}$ & $0.661^{* *}$ \\
\hline FMI & $0.264^{* *}$ & $0.603^{* *}$ & -0.001 & 0.019 & $0.427^{* *}$ & $0.593^{* *}$ & 0.172 & 0.195 & $0.642^{* *}$ \\
\hline FFM & $0.819^{* *}$ & $0.690^{* *}$ & $0.369^{* *}$ & $0.409^{* *}$ & $0.567^{* *}$ & $0.646^{* *}$ & $0.309^{* *}$ & $0.480^{* *}$ & $0.614^{* *}$ \\
\hline FFMI & $0.746^{* *}$ & $0.614^{* *}$ & 0.042 & $0.364^{* *}$ & $0.380^{* *}$ & $0.543^{* *}$ & -0.108 & 0.205 & $0.583^{* *}$ \\
\hline TBW & $0.245^{* *}$ & $-0.288^{* *}$ & -0.189 & -0.071 & 0.063 & $-0.225^{* *}$ & $-0.330^{* *}$ & $-0.265^{*}$ & -0.099 \\
\hline $\mathrm{VO}_{2}$ & $0.945^{* *}$ & $0.992^{* *}$ & $0.986^{* *}$ & $0.991^{* *}$ & $0.989^{* *}$ & $0.977^{* *}$ & $0.988^{* *}$ & $0.939^{* *}$ & $0.993^{* *}$ \\
\hline $\mathrm{VCO}_{2}$ & $0.991^{* *}$ & $0.914^{* *}$ & $0.810^{* *}$ & $0.901^{* *}$ & $0.872^{* *}$ & $0.899^{* *}$ & $0.819^{* *}$ & $0.903^{* *}$ & $0.878^{* *}$ \\
\hline
\end{tabular}

$\mathrm{Ht}$, height; Wt, weight; BMI, body mass index; IBW, ideal body weight by the Hamwi equation; AdjWt, adjusted body weight; WC, waist circumference; HC, hip circumference; WHR, waist hip ratio; MAC, midarm circumference; TST, triceps skinfold thickness; MAMA, midarm muscular area; PBF, percent body fat; FM, fat mass; FMI, fat mass index; FFM, fat-free mass; FFMI, fat-free mass index; TBW, total body water; $\mathrm{RMR}$, resting metabolic rate; $\mathrm{VO}_{2}$, volume of $\mathrm{O}_{2}$ inspired per minute; $\mathrm{VCO}_{2}$, volume of $\mathrm{CO}_{2}$ expired per minute; ${ }^{* *}$ correlation is significant at the 0.01 level (2-tailed); ${ }^{*}$ correlation is significant at the 0.05 level (two-tailed). 
TABLE 5: New predictive equations among total population.

\begin{tabular}{|c|c|c|c|c|c|}
\hline Independent variables & $\begin{array}{c}\text { Stepwise } \\
\text { entry } \\
\text { of variables }\end{array}$ & $R$ & $R$ square & $\begin{array}{l}\text { Adjusted } \\
R \text { square }\end{array}$ & Equation \\
\hline $\begin{array}{l}\text { Total }(n=423) \\
\text { Age, gender, Ht, Wt, } \\
\text { BMI, IBW, AdjWt, } \\
\text { WC, HC, WHR, MAC, } \\
\text { TST, MAMA }\end{array}$ & $\begin{array}{l}\text { AdjWt } \\
\text { Ht } \\
\text { Gender } \\
\text { Age }\end{array}$ & $\begin{array}{l}0.787 \\
0.821 \\
0.834 \\
0.838\end{array}$ & $\begin{array}{l}0.620 \\
0.674 \\
0.695 \\
0.702\end{array}$ & $\begin{array}{l}0.619 \\
0.672 \\
0.693 \\
0.699\end{array}$ & $\begin{array}{c}\mathrm{REE}=3832.955+\text { AdjWt } \times 48.037-\mathrm{Ht}(\mathrm{cm}) \times \\
30.642+\text { gender* } \times 141.268-\text { age } \times 4.525 \\
(\text { equation AA_1) }\end{array}$ \\
\hline $\begin{array}{l}\text { Gender, PBF, FM, } \\
\text { FMI, FFM, FFMI, } \\
\text { TBW }\end{array}$ & $\begin{array}{l}\text { FFM } \\
\text { TBW } \\
\text { Gender } \\
\text { FM }\end{array}$ & $\begin{array}{l}0.819 \\
0.832 \\
0.835 \\
0.842\end{array}$ & $\begin{array}{l}0.671 \\
0.692 \\
0.698 \\
0.708\end{array}$ & $\begin{array}{l}0.670 \\
0.691 \\
0.696 \\
0.706\end{array}$ & $\begin{aligned} \mathrm{REE}=683.588+ & \mathrm{FFM} \times 21.168-\mathrm{TBW} \times 6.119+\text { gender }^{*} \times \\
& 208.529+\mathrm{FM} \times 5.704 \\
& (\text { equation AA_FFM })\end{aligned}$ \\
\hline $\begin{array}{l}\text { Normal weight populat } \\
\text { Age, gender, Ht, Wt, } \\
\text { BMI, WC, HC, WHR, } \\
\text { MAC, TST, MAMA }\end{array}$ & $\begin{array}{c}(n=134) \\
\mathrm{Ht} \\
\text { Gender }\end{array}$ & $\begin{array}{l}0.746 \\
0.784\end{array}$ & $\begin{array}{l}0.556 \\
0.615\end{array}$ & 0.553 & $\begin{array}{c}\mathrm{REE}=\mathrm{Ht} \times 14.923+\text { gender }^{*} \times 202.170-990.796 \\
\text { (equation AA_2) }\end{array}$ \\
\hline $\begin{array}{l}\text { Age, gender, PBF, FM, } \\
\text { FMI, FFM, TBW }\end{array}$ & $\begin{array}{l}\text { FFM } \\
\text { TBW } \\
\text { Gender } \\
\text { Age }\end{array}$ & $\begin{array}{l}0.745 \\
0.763 \\
0.789 \\
0.798 \\
\end{array}$ & $\begin{array}{l}0.555 \\
0.582 \\
0.622 \\
0.637\end{array}$ & $\begin{array}{l}0.551 \\
0.576 \\
0.613 \\
0.625\end{array}$ & $\begin{array}{c}\mathrm{REE}=1053.737+\mathrm{FFM} \times 19.536-\mathrm{TBW} \times 6.664+ \\
\text { gender }^{*} \times 196.446-\text { age } \times 6.445\end{array}$ \\
\hline $\begin{array}{l}\text { Over Wt and obese }(n= \\
\text { Age, gender, Ht, Wt, } \\
\text { BMI, IBW, AdjWt, } \\
\text { WC, HC, WHR, MAC, } \\
\text { TST, MAMA }\end{array}$ & $\begin{array}{l}\text { 39) AdjWt } \\
\text { Ht } \\
\text { Gender } \\
\text { Age }\end{array}$ & $\begin{array}{l}0.763 \\
0.798 \\
0.813 \\
0.817\end{array}$ & $\begin{array}{l}0.582 \\
0.637 \\
0.661 \\
0.668\end{array}$ & $\begin{array}{l}0.580 \\
0.634 \\
0.657 \\
0.663\end{array}$ & $\begin{array}{c}\mathrm{REE}=4128.975+\text { AdjWt } \times 49.455-\mathrm{Ht}(\mathrm{cm}) \times \\
33.117+\text { gender }^{*} \times 160.727-\text { age } \times 4.207 \\
(\text { equation AA_3) }\end{array}$ \\
\hline $\begin{array}{l}\text { Age, gender, PBF, FM, } \\
\text { FMI, FFM, FFMI, } \\
\text { TBW }\end{array}$ & $\begin{array}{l}\text { FFM } \\
\text { TBW } \\
\text { Age }\end{array}$ & $\begin{array}{l}0.800 \\
0.815 \\
0.819\end{array}$ & $\begin{array}{l}0.640 \\
0.664 \\
0.671\end{array}$ & $\begin{array}{l}0.639 \\
0.661 \\
0.667\end{array}$ & $\mathrm{REE}=712.703+\mathrm{FFM} \times 30.735-\mathrm{TBW} \times 9.738-$ age $\times 4.180$ \\
\hline
\end{tabular}

${ }^{*}$ Gender for men use 1 and for women use 0 . AdjWt is Adjusted body weight $=\mathrm{IBW}+0.25 \times(\mathrm{Wt}-\mathrm{IBW})$. IBW is Ideal body weight; for men $\mathrm{IBW}=(\mathrm{Ht}(\mathrm{cm})-152.4) \times 1.0714)+45.36$ and for women $\mathrm{IBW}=(\mathrm{Ht}(\mathrm{cm})-152.4) \times 0.8928)+45.36$.

TABLE 6: New predictive equations among men.

\begin{tabular}{|c|c|c|c|c|c|}
\hline Independent variables & $\begin{array}{c}\text { Stepwise entry of } \\
\text { variables }\end{array}$ & $R$ & $\begin{array}{c}R \\
\text { square } \\
\end{array}$ & $\begin{array}{c}\text { Adjusted } R \\
\text { square }\end{array}$ & Equation \\
\hline \multicolumn{6}{|l|}{ All men $(n=208)$} \\
\hline Age, Ht, Wt, BMI, IBW, AdjWt, WC, & Wt & 0.724 & 0.524 & 0.521 & \multirow{2}{*}{$\mathrm{REE}=910.062+\mathrm{Wt} \times 20.046-\mathrm{BMI} \times 21.003$} \\
\hline HC, WHR, MAC, TST, MAMA & BMI & 0.733 & 0.537 & 0.533 & \\
\hline Age, PBF, FM, FMI, FFM, FFMI, & FFM & 0.696 & 0.484 & 0.482 & \multirow{2}{*}{$\mathrm{REE}=591.198+\mathrm{FFM} \times 19.555-\mathrm{FM} \times 9.219$} \\
\hline TBW & FM & 0.731 & 0.534 & 0.529 & \\
\hline \multicolumn{6}{|l|}{ Normal weight men $(n=59)$} \\
\hline $\begin{array}{l}\text { Age, Ht, Wt, BMI, WC, HC, WHR, } \\
\text { MAC, TST, MAMA }\end{array}$ & $\mathrm{Ht}$ & 0.477 & 0.227 & 0.214 & $\mathrm{REE}=\mathrm{Ht} \times 18.035-1320.610$ \\
\hline \multirow{2}{*}{ Age, PBF, FM, FMI, FFM, TBW } & FFM & 0.369 & 0.136 & 0.121 & \multirow{2}{*}{$\mathrm{REE}=1193.657+\mathrm{FFM} \times 18.076-\mathrm{TBW} \times 6.971$} \\
\hline & TBW & 0.451 & 0.204 & 0.175 & \\
\hline \multicolumn{6}{|l|}{ Over Wt and obese men $(n=149)$} \\
\hline $\begin{array}{l}\text { Age, Ht, Wt, BMI, IBW, AdjWt, WC, } \\
\text { HC, WHR, MAC, TST, MAMA }\end{array}$ & $\mathrm{Wt}$ & 0.673 & 0.453 & 0.449 & \multirow[t]{3}{*}{$\mathrm{REE}=852.567+\mathrm{Wt} \times 13.342$} \\
\hline Age, PBF, FM, FMI, FFM, FFMI, & FFM & 0.644 & 0.415 & 0.411 & \\
\hline TBW & FM & 0.682 & 0.465 & 0.458 & \\
\hline
\end{tabular}

(Bernstein) to $4.3 \%\left(\mathrm{H}-\mathrm{B}^{1919}\right)$ in men and from $24.7 \%$ (Bernstein) to $0.4 \%$ (Schofield ${ }^{\mathrm{W}}$ ) in women (Table 2 ). These results suggest no predictive equation was suitable to predict REE in men as all 10 predictive equations demonstrated bias of $>1 \%$. In women, only two equations $\left(\mathrm{WHO}^{\mathrm{W}}\right.$ and Schofield ${ }^{\mathrm{W}}$ ) had bias of $<1 \%$ (Table 3 ). Our findings (Table 3 ) showed that some of the predictive equations $\left(\mathrm{WHO}^{\mathrm{WH}}, \mathrm{WHO}^{\mathrm{W}}\right.$, Schofield ${ }^{\mathrm{WH}}$, and
Schofield ${ }^{\mathrm{W}}$ ) had relatively high $\%$ accurate prediction $(>50$ and $<60 \%$ ) but with $>1 \%$ bias and can be used for REE estimation at the population levels in Saudi men. Similarly, in women, our data (Table 4) showed that some equations $\left(\mathrm{H}-\mathrm{B}^{1984}\right.$, H-B ${ }^{1919}$, WHO ${ }^{\mathrm{WH}}$, WHO ${ }^{\mathrm{W}}$, Schofield ${ }^{\mathrm{WH}}$, Schofield $^{\mathrm{W}}$, and Mifflin) had relatively high percentage accurate prediction $(>50<60 \%)$, but only two equations $\left(\mathrm{WHO}^{\mathrm{W}}\right.$ and Schofield ${ }^{\mathrm{W}}$ ) had bias of $<1 \%$ and can be used 
TABLE 7: New predictive equations among women.

\begin{tabular}{|c|c|c|c|c|c|}
\hline $\begin{array}{l}\text { Independent } \\
\text { variables }\end{array}$ & $\begin{array}{l}\text { Stepwise entry of } \\
\text { variables }\end{array}$ & $R$ & $R$ Square & $\begin{array}{l}\text { Adjusted } \\
R \text { square }\end{array}$ & Equation \\
\hline \multicolumn{6}{|l|}{ All women $(n=215)$} \\
\hline Age, $\mathrm{Ht}, \mathrm{Wt}, \mathrm{BMI}, \mathrm{IBW}$, & $\mathrm{Wt}$ & 0.663 & 0.440 & 0.437 & \multirow{4}{*}{$\begin{array}{c}\mathrm{REE}=972.009+\mathrm{Wt} \times 15.278- \\
\text { age } \times 5.369-\mathrm{MAC} \times 11.674\end{array}$} \\
\hline AdjWt, WC, HC, WHR, & Age & 0.686 & 0.470 & 0.465 & \\
\hline \multirow[t]{2}{*}{ MAC, TST, MAMA } & MAC & 0.695 & 0.483 & 0.476 & \\
\hline & FFM & 0.646 & 0.417 & 0.415 & \\
\hline Age, PBF, FM, FMI, FFM, & TBW & 0.705 & 0.496 & 0.492 & \multirow{3}{*}{$\begin{aligned} \mathrm{REE}= & 745.607+\mathrm{FFM} \times 24.818-\mathrm{TBW} \times 7.185 \\
& - \text { age } \times 5.793+\mathrm{FMI} \times 14.472\end{aligned}$} \\
\hline \multirow[t]{2}{*}{ FFMI, TBW } & Age & 0.718 & 0.516 & 0.509 & \\
\hline & FMI & 0.733 & 0.537 & 0.528 & \\
\hline \multicolumn{6}{|l|}{ Normal weight women $(n=75)$} \\
\hline $\begin{array}{l}\text { Age, } \mathrm{Ht}, \mathrm{Wt}, \mathrm{BMI}, \mathrm{WC}, \mathrm{HC} \\
\text { WHR, MAC, TST, MAMA }\end{array}$ & $\mathrm{Ht}$ & 0.418 & 0.175 & 0.164 & $\mathrm{REE}=\mathrm{Ht} \times 12.086-542.676$ \\
\hline \multirow{3}{*}{$\begin{array}{l}\text { Age, PBF, FM, FMI, FFM, } \\
\text { FFMI, TBW }\end{array}$} & TBW & 0.330 & 0.109 & 0.097 & \multirow{3}{*}{$\begin{aligned} \mathrm{REE}=966.832- & \mathrm{TBW} \times 6.029+\mathrm{FFM} \times 22.696 \\
& -\operatorname{age} \times 8.674\end{aligned}$} \\
\hline & FFM & 0.485 & 0.236 & 0.214 & \\
\hline & Age & 0.559 & 0.312 & 0.283 & \\
\hline \multicolumn{6}{|c|}{ Over Wt and obese women $(n=140)$} \\
\hline Age, $\mathrm{Ht}, \mathrm{Wt}, \mathrm{BMI}, \mathrm{IBW}$ & $\mathrm{Wt}$ & 0.602 & 0.362 & 0.358 & \multirow[b]{2}{*}{$\mathrm{REE}=794.871+\mathrm{Wt} \times 12.565-$ age $\times 5.499$} \\
\hline $\begin{array}{l}\text { AdjWt, WC, HC, WHR, } \\
\text { MAC, TST, MAMA }\end{array}$ & Age & 0.628 & 0.394 & 0.386 & \\
\hline Age, PBF, FM, FMI, FFM, & FFM & 0.590 & 0.348 & 0.343 & \multirow{2}{*}{$\mathrm{REE}=602.841+\mathrm{FFM} \times 32.399-\mathrm{TBW} \times 12.578$} \\
\hline FFMI, TBW & TBW & 0.670 & 0.449 & 0.441 & \\
\hline
\end{tabular}

TABLE 8: General characteristics of subjects used for external validation.

\begin{tabular}{|c|c|c|c|c|}
\hline Variables & $\begin{array}{c}\text { Total } \\
\text { Mean } \pm \text { SD }(n=48)\end{array}$ & $\begin{array}{c}\text { Men } \\
\text { Mean } \pm \text { SD }(n=24)\end{array}$ & $\begin{array}{c}\text { Women } \\
\text { Mean } \pm \text { SD }(n=24)\end{array}$ & $P$ value \\
\hline Age (year) & $29.94 \pm 8.39$ & $28.42 \pm 10.00$ & $31.46 \pm 6.25$ & NS \\
\hline $\mathrm{Ht}(\mathrm{cm})$ & $164.33 \pm 7.90$ & $170.46 \pm 4.85$ & $158.19 \pm 5.06$ & $P<0.001$ \\
\hline Wt (kg) & $79.69 \pm 17.40$ & $85.27 \pm 19.90$ & $74.11 \pm 12.54$ & $P<0.05$ \\
\hline BMI $\left(\mathrm{kg} / \mathrm{m}^{2}\right)$ & $29.44 \pm 5.67$ & $29.33 \pm 6.83$ & $29.56 \pm 4.37$ & NS \\
\hline IBW & $57.74 \pm 8.65$ & $64.84 \pm 5.20$ & $50.64 \pm 4.52$ & $P<0.001$ \\
\hline AdjWt & $63.23 \pm 9.23$ & $69.95 \pm 6.93$ & $56.51 \pm 5.62$ & $P<0.001$ \\
\hline $\mathrm{WC}(\mathrm{cm})$ & $89.89 \pm 12.95$ & $92.75 \pm 16.01$ & $87.03 \pm 8.32$ & NS \\
\hline $\mathrm{HC}(\mathrm{cm})$ & $106.12 \pm 11.85$ & $104.13 \pm 13.89$ & $108.11 \pm 9.25$ & NS \\
\hline WHR & $0.85 \pm 0.07$ & $0.89 \pm 0.06$ & $0.81 \pm 0.06$ & $P<0.001$ \\
\hline $\operatorname{MAC}(\mathrm{cm})$ & $30.61 \pm 4.62$ & $29.02 \pm 4.83$ & $32.21 \pm 3.88$ & $P<0.05$ \\
\hline TST (mm) & $27.81 \pm 8.94$ & $24.56 \pm 9.05$ & $31.05 \pm 7.72$ & $P<0.05$ \\
\hline MAMA $\left(\mathrm{cm}^{2}\right)$ & $39.14 \pm 13.61$ & $37.20 \pm 14.08$ & $41.07 \pm 13.14$ & NS \\
\hline PBF (\%) & $32.10 \pm 9.52$ & $25.43 \pm 8.17$ & $38.78 \pm 5.04$ & $P<0.001$ \\
\hline FM (kg) & $26.06 \pm 11.12$ & $22.86 \pm 12.62$ & $29.25 \pm 8.48$ & $P<0.05$ \\
\hline FFM (kg) & $53.38 \pm 11.08$ & $61.91 \pm 8.85$ & $44.85 \pm 4.55$ & $P<0.001$ \\
\hline TBW (L) & $48.30 \pm 9.27$ & $55.12 \pm 5.42$ & $41.49 \pm 7.00$ & $P<0.001$ \\
\hline RMR (kcal/day) & $1737.52 \pm 378.49$ & $1971.17 \pm 386.37$ & $1503.86 \pm 171.84$ & $P<0.001$ \\
\hline RQ & $0.74 \pm 0.07$ & $0.78 \pm 0.06$ & $0.69 \pm 0.06$ & $P<0.001$ \\
\hline
\end{tabular}

for REE estimation at the population levels for Saudi women. However, none of the 10 equations used for comparison in the current study can be reliably used to assess individual differences, as they are likely to provide inaccurate results in clinical settings.

Based on these data, four main lines of arguments can be drawn: (1) all nine predictive equations used in this study underpredicted REE in men, while most (eight out of nine) predictive equations underestimated REE for women, but two $\left(\mathrm{WHO}^{\mathrm{W}}(\mathrm{Wt})\right.$ and Schofield $\left.{ }^{\mathrm{WT}}\right)$ overpredicted $\mathrm{REE}$ in women; (2) predictive equations that underpredicted REE in men mostly overpredicted those in women; (3) predictive equations overpredicted REE at the higher REE level (e.g., men in this study) and underpredicted REE mostly at lower REE levels (as in women), an observation in contrast to that by Müller et al. [3]; and (4) only two of these predictive equations $\left(\mathrm{WHO}^{\mathrm{W}}\right.$ and Schofield ${ }^{\mathrm{W}}$ ) showed an acceptable REEp/REEm difference of $<1 \%$ and an accurate prediction $(\sim 55 \%)$ at the individual level [36]. Therefore, we would recommend the use of the equations we developed (AA equation) based on a mixture of men and women and that would offer the possibility to cover individuals with a wider BMI range $\left(18-31 \mathrm{~kg} / \mathrm{m}^{2}\right)$.

WHO formulae are widely used to predict REE. These equations are based on considerably a large number of REE measurements performed in the twentieth century. 
TABLE 9: Accuracy of the new equations vs resting metabolic rate measured by indirect calorimetry and that calculated by some predictive equations in population used for external validation $(n=48$; men: $50 \%)$.

\begin{tabular}{|c|c|c|c|c|c|c|c|}
\hline Tools & RMR (kcal/day) & Bias (kcal) & $\begin{array}{c}\text { Percent of bias } \\
(\%)\end{array}$ & $\begin{array}{c}\text { Underestimation } \\
(\%)\end{array}$ & $\begin{array}{c}\text { Overestimation } \\
(\%) \\
\end{array}$ & $\begin{array}{c}\text { Accurate estimation } \\
(\%)\end{array}$ & $r$ \\
\hline $\begin{array}{l}\text { Measured } \\
\text { RMR }\end{array}$ & $1737.52 \pm 378.49$ & - & - & - & - & - & - \\
\hline AA_1 & $1770.15 \pm 296.80$ & $32.63 \pm 219.84$ & $2.00 \pm 11.72$ & 14.58 & 25.00 & 60.42 & $0.815^{* *}$ \\
\hline AA_FFM & $1770.94 \pm 313.25$ & $33.41 \pm 219.60$ & $1.90 \pm 11.49$ & 14.58 & 22.92 & 62.50 & $0.815^{* *}$ \\
\hline НВ 1919 & $1704.65 \pm 292.18$ & $32.87 \pm 227.50$ & $1.81 \pm 12.62$ & 16.67 & 22.92 & 60.42 & $0.800^{* * *}$ \\
\hline Bernstein & $1362.08 \pm 218.08^{* *}$ & $375.44 \pm 248.63$ & $27.32 \pm 17.12$ & 87.50 & 0.00 & 12.50 & $0.781^{* *}$ \\
\hline Owen & $1537.92 \pm 263.66^{* *}$ & $199.60 \pm 224.21$ & $12.86 \pm 13.29$ & 58.33 & 4.17 & 37.50 & $0.814^{* *}$ \\
\hline Mifflin & $1597.84 \pm 256.53^{* *}$ & $139.68 \pm 229.47$ & $8.51 \pm 13.34$ & 35.42 & 4.17 & 60.42 & $0.805^{* *}$ \\
\hline
\end{tabular}

AA_1 and AA_FMM are the newly developed equations. Bias = RMR measured by Quark RMR-REE predicted by equations; percent of bias $=[($ RMR measured by Quark RMR-REE predicted by equations) * 100]/REE predicted by equations; accurate estimation = percentage of all subjects whose REE was within $90 \%$ to $110 \%$ of measured RMR by Quark RMR; underestimation = percentage of all subjects whose REE was less than $90 \%$ of measured RMR by Quark RMR; overestimation = percentage of all subjects whose REE was more than $110 \%$ of measured RMR by Quark RMR; $r$, Pearson's correlation coefficient between RMR measured by Quark RMR and REE predicted by equations.** Significant $(P<0.001)$.

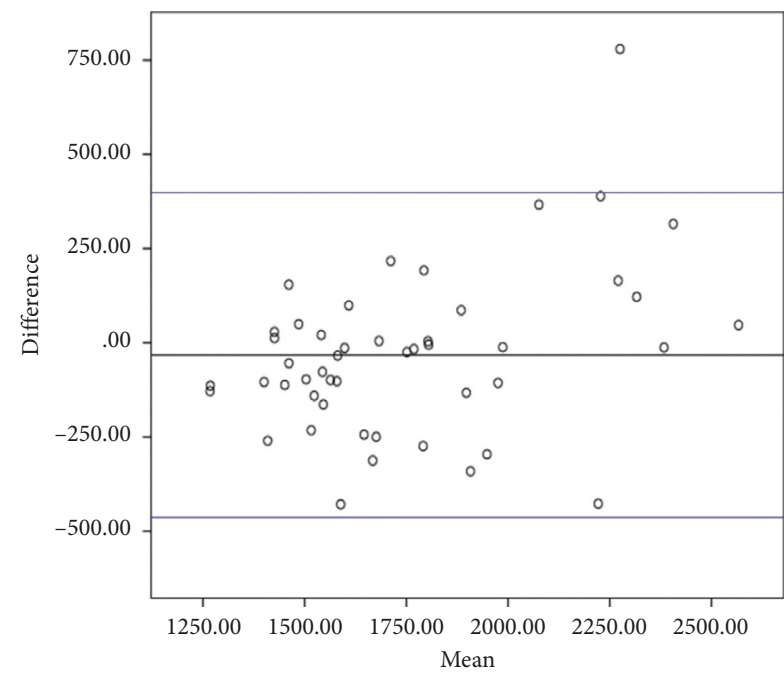

(a)

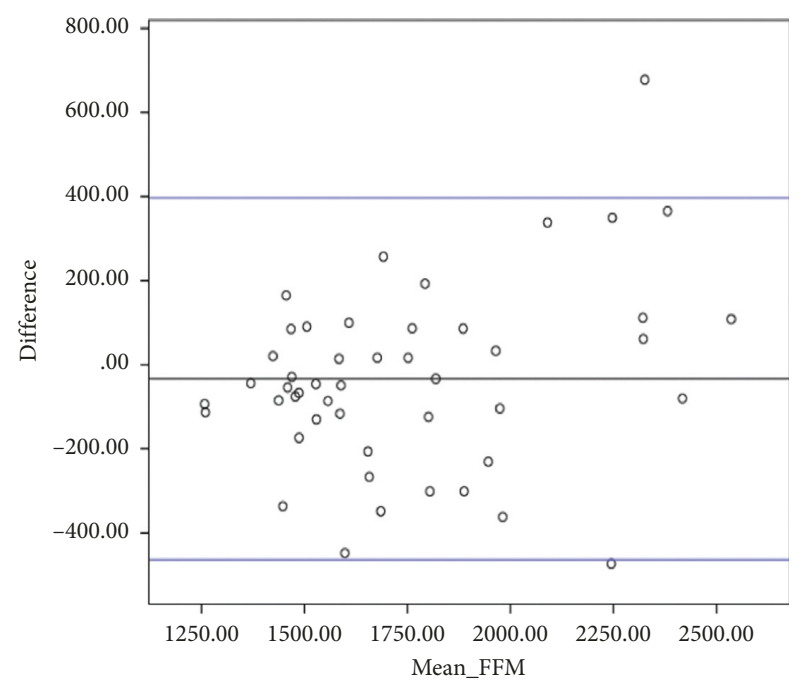

(b)

FIgURe 4: Bland-Altman plots showing the agreement of indirect calorimetry (IC) and the new equations for resting metabolic rate in the population used for external validation: (a) AA_1 and (b) AA_FFM.

Although some more recent formulae have been provided by other authors, one shortcoming is that none of these equations were based on a comparably large database [37]. The Owen equation was derived on 44 otherwise healthy obese and women between 18 and 65 years of age and 60 obese and lean men between 18 and 82 years of age [8]. The Mifflin equation was derived from data of 498 healthy subjects (251 men/247 women; aged 19 to 78 years, with 234 obese and 264 had normal weight) [9]. These equations are commonly used in clinical practice. The accuracy rates of the Owen equation are $37.0 \%$ and $37.7 \%$, respectively; men and women and those of the Mifflin equation are $44.2 \%$ and $52.6 \%$, respectively. The accuracy rates of these two equations are comparable to the recently conducted studies, e.g., Rao et al. [38], in Chinese population. However, these equations had a higher percentage bias in both Saudi men and women (Table 4) and, therefore, cannot be recommended in Saudi population and REE prediction in the clinical setting.
The WHO equation was developed on a study of young Europeans, mostly police and military recruits, with a high proportion (45\%) being of the Italian descent [32]. In our study, the subjects were Saudi adults from the civil community. This might explain that despite the relatively higher accuracy of $\mathrm{WHO}^{\mathrm{WT}}$ and $\mathrm{WHO}^{\mathrm{W}}$ equations in women (56.8\% and $55.3 \%$, respectively), only $\mathrm{WHO}^{\mathrm{W}}$ had a percentage bias of $<1.0$. Therefore, WHO equations (both $\mathrm{WHO}^{\mathrm{WT}}$ and $\mathrm{WHO}^{\mathrm{W}}$ ) may not be suitable for, at least, Saudi men. As also argued by De Oliveira et al. [39] and Owen et al. [8], $\mathrm{WHO}^{\mathrm{W}}$ is the most suitable equation for normal weight individuals [40], and with some restrictions, Mifflin's equation has been indicated suitable for REE estimation in normal, overweight, and obese individuals in the United States [7]; however, this might not be as much true in other populations. Based on some previous studies [41-43], there are no suitable equations for overweight/obese persons [39]. Mifflin's equation was developed using data from 498 individuals classified as normal, overweight, and obese/ 
seriously obese [9]; despite its validation in other communities, it is most suitable for the American individuals with a BMI range of 25 to $40 \mathrm{~kg} / \mathrm{m}^{2}$ and aged 16-65 years [34]. However, we did not observe a good relationship between Mifflin's equation and overweight individuals in the present study. The Mifflin equation was proved as a good equation for estimating REE in western population with various body masses [7]; however, this was not the case in our population (Tables 4 and 9). The underestimation while using the Owen equation was not unexpected because of its reliability for normal weight populations, which presents lower REE than for that for obese individuals [40].

This study has a number of strengths. The sample size (427 individuals) was large enough for subgroup (men and women) analyses. Furthermore, the data were derived from otherwise healthy individuals (normal BMI, overweight, and obese), and therefore, the study population may be representative for a wider BMI subjects and hence has large generalizability. The prediction equation we developed in this study is the first, to our knowledge, that is specifically adjusted for Arab ethnicity. This study included women representing a wide range of body weight, a fact which may increase the generalizability of the newly developed equation to other samples. Finally, we carefully controlled for the effects of several potentially important confounders, such as menopausal status, menstrual cycle, pregnancy/lactation, other relevant medical conditions, and the possible thermogenic effects of food and nicotine. However, there are several limitations in this study as well. First, the investigation did not include subjects with BMI $<18.5$ (underweight), which is still relatively a substantial fraction of the total population and their underrepresentation may cause a decrease in the generalizability of the new equation. Second, the sample was limited to men and women aged 18-57 years; thus, the predictive value of the new equation in estimating REE among older men and women may be uncertain. Future investigations should focus on the impact of ethnicity on the accuracy of prediction equations that have been developed for older Saudi men and women, e.g., study by Arciero et al. [19]. For this future, studies should focus on examining whether equations for predicting REE should be modified/adjusted for use in other ethnic groups. In addition, although the AA equation may provide good estimates of REE needs, a nontrivial amount of REE variance remains unaccounted. Nevertheless, REE variance accounted using the prediction equation is consistent with that of the previous studies.

In conclusion, we found in the present study that REE predictive equations are only accurate in approximately half the individuals. The WHO equation is advised for use up to BMI $30 \mathrm{~kg} / \mathrm{m}^{2}$, and $\mathrm{HB}^{1918}$ equation is advised for obese individuals (BMI of $>30 \mathrm{~kg} / \mathrm{m}^{2}$ ). Measuring REE with indirect calorimetry is the preferred option and should be used when the facility is available as well as feasible for the optimization of nutritional support in hospital in- and outpatients with different degrees of malnutrition. In case of nonavailability/ unfeasibility of the facility, we recommend use of a population-specific predictive equation. Future validation of other equations developed in this study is required using adequate samples.

\section{Data Availability}

The original data used to support the findings of this study are available from the corresponding author upon request.

\section{Disclosure}

The abstract of this manuscript was presented as a poster in the annual meeting of the American Society for Nutrition, $\mathrm{Nu}-$ trition 2019, and published as a supplement in the following link: https://academic.oup.com/cdn/article/3/Supplement_1/ nzz050.P16-048-19/5517188.

\section{Conflicts of Interest}

The authors declare that they have no conflicts of interest.

\section{Authors' Contributions}

AMA designed the study protocol, wrote the manuscript, and helped in data collection and analysis. MMAA took care of IC, processing, and analysis of data and also helped in writing the manuscript.

\section{Acknowledgments}

The authors greatly appreciate MARRIFAH of the King Abdul-Aziz City for Science and Technology for funding this project (grant number 11-MED1966-02). Additionally, the authors thank RSSU of the Deanship of Scientific Research at King Saud University for editing this paper.

\section{Supplementary Materials}

A simplified calculator for the main equations (AA_1 and AA_FFM). Instruction for use: according to the gender, please either insert the age, weight, and height or the bioelectrical impedance data such as FFM, FM, and TBW and then get the RMR in kcal/day. (Supplementary Materials)

\section{References}

[1] K. Melzer, V. Laurie Karsegard, L. Genton, M. P. Kossovsky, B. Kayser, and C. Pichard, "Comparison of equations for estimating resting metabolic rate in healthy subjects over 70 years of age," Clinical Nutrition, vol. 26, no. 4, pp. 498-505, 2007.

[2] J. A. Harris and F. G. Benedict, "A Biometric study of human basal metabolism," Proceedings of the National Academy of Sciences, vol. 4, no. 12, pp. 370-373, 1918.

[3] M. J. Müller, A. Bosy-Westphal, S. Klaus et al., "World Health Organization equations have shortcomings for predicting resting energy expenditure in persons from a modern, affluent population: generation of a new reference standard from a retrospective analysis of a German database of resting energy expenditure," The American Journal of Clinical Nutrition, vol. 80, no. 5, pp. 1379-1390, 2004.

[4] D. Frankenfield, J. Smith, and R. Cooney, "Validation of 2 approaches to predicting resting metabolic rate in critically ill patients," Journal of Parenteral and Enteral Nutrition, vol. 28, no. 4, pp. 259-264, 2004. 
[5] P. J. M. Weijs, H. M. Kruizenga, A. E. van Dijk et al., "Validation of predictive equations for resting energy expenditure in adult outpatients and inpatients," Clinical $\mathrm{Nu}$ trition, vol. 27, no. 1, pp. 150-157, 2008.

[6] B. Wilms, S. M. Schmid, B. Ernst, M. Thurnheer, M. J. Mueller, and B. Schultes, "Poor prediction of resting energy expenditure in obese women by established equations," Metabolism, vol. 59, no. 8, pp. 1181-1189, 2010.

[7] D. C. Frankenfield, "Bias and accuracy of resting metabolic rate equations in non-obese and obese adults," Clinical $\mathrm{Nu}$ trition, vol. 32, no. 6, pp. 976-982, 2013.

[8] O. E. Owen, E. Kavle, R. S. Owen et al., "A reappraisal of caloric requirements in healthy women," The American Journal of Clinical Nutrition, vol. 44, no. 1, pp. 1-19, 1986.

[9] M. D. Mifflin, S. T. St Jeor, L. A. Hill, B. J. Scott, S. A. Daugherty, and Y. O. Koh, "A new predictive equation for resting energy expenditure in healthy individuals," The American Journal of Clinical Nutrition, vol. 51, no. 2, pp. 241-247, 1990.

[10] R. S. Bernstein, J. C. Thornton, M. U. Yang et al., "Prediction of the resting metabolic rate in obese patients," The American Journal of Clinical Nutrition, vol. 37, no. 4, pp. 595-602, 1983.

[11] FAO/WHO/UNU, Energy and Protein Requirements: Report of a Joint FAO/WHO/UNU Expert Consultation, World Health Organanisation Technical Report Series, World Health Organanisation, Geneva, Switzerland, 1985.

[12] W. N. Schofield, "Predicting basal metabolic rate, new standards and review of previous work," Human Nutrition: Clinical Nutrition, vol. 39, pp. 5-41, 1985.

[13] J. R. Speakman and C. Selman, "Physical activity and resting metabolic rate," Proceedings of the Nutrition Society, vol. 62, no. 3, pp. 621-634, 2003.

[14] J. P. DeLany, "Energy requirement methodology," in Nutrition in the Prevention and Treatment of Disease, A. M. Coulston, C. J. Boushey, and M. Ferruzzi, Eds., pp. 81-83, Academic Press, New York, NY, USA, 3rd edition, 2013.

[15] G. W. Horgan and J. Stubbs, "Predicting basal metabolic rate in the obese is difficult," European Journal of Clinical Nutrition, vol. 57, no. 2, pp. 335-340, 2003.

[16] P. Shetty, "Adaptation to low energy intakes: the responses and limits to low intakes in infants, children and adults," European Journal of Clinical Nutrition, vol. 53, no. S1, pp. S14-s33, 1999.

[17] A. E. Black, W. A. Coward, T. J. Cole, and A. M. Prentice, "Human energy expenditure in affluent societies: an analysis of 574 doubly-labeled water measurements," European Journal of Clinical Nutrition, vol. 50, pp. 72-92, 1996.

[18] P. Shetty, C. J. K. Henry, A. E. Black, and A. M. Prentice, "Energy requirements of adults: an update on basal metabolic rates (BMRs) and physical activity levels (PALs)," European Journal of Clinical Nutrition, vol. 50, no. 1, pp. S11-S23, 1996.

[19] P. J. Arciero, M. I. Goran, A. M. Gardner, P. A. Ades, R. S. Tyzbir, and E. T. Poehlman, "A practical equation to predict resting metabolic rate in older females," Journal of the American Geriatrics Society, vol. 41, no. 4, pp. 389-395, 1993.

[20] M. J. Soares, D. G. Francis, and P. S. Shetty, "Predictive equations for basal metabolic rates of Indian males," European Journal of Clinical Nutrition, vol. 47, pp. 389-394, 1993.

[21] C. M. Cruz, A. F. daSilva, and L. A. dos Anjos, "A taxa metabica basal e superestimade pelas equa co es preditivas em universitaras do Rio de Janeiro, Brasil," Archivio Latino Americano Nutricion, vol. 49, pp. 232-237, 1999.
[22] D. Gallagher, J. Albu, Q. He et al., "Small organs with a high metabolic rate explain lower resting energy expenditure in African American than in white adults," The American Journal of Clinical Nutrition, vol. 83, no. 5, pp. 1062-1067, 2006.

[23] B. Gannon, L. DiPietro, and E. Poehlman, "Do African Americans have lower energy expenditure than Caucasians?," International Journal of Obesity, vol. 24, no. 1, pp. 4-13, 2000.

[24] T. H. Merghani, A. O. Alawad, R. M. Ibrahim, and A. M. Abdelmoniem, "Prediction of basal metabolic rate in overweight/obese and non-obese subjects and its relation to pulmonary function tests," BMC Research Notes, vol. 8, p. 353, 2015.

[25] A. Hassan, A. Mahdi, L. Hamade, A. Kerkadi, and A. Yousef, "Resting energy expenditure in a controlled group of young Arab females: correlations with body composition and agreement with prediction equations," Food and Nutrition Sciences, vol. 4, no. 4, pp. 385-391, 2013.

[26] T. H. Merghani, A. O. Alawad, and M. A. Ballal, "Plasma TNF- $\alpha$ in obese patients with diabetes and its relation to resting metabolic rate," Journal of Diabetology, vol. 5, no. 1, pp. 1-6, 2014.

[27] A. M. Almajwal, P. G. Williams, and M. J. Batterham, "Validity of the BodyGem calorimeter and prediction equations for the assessment of resting energy expenditure in overweight and obese Saudi males," Saudi Medical Journal, vol. 32, no. 7, pp. 718-724, 2011.

[28] M. W. Vander Weg, J. M. Watson, R. C. Klesges, L. H. Eck Clemens, D. L. Slawson, and B. S. McClanahan, "Development and cross-validation of a prediction equation for estimating resting energy expenditure in healthy AfricanAmerican and European-American women," European Journal of Clinical Nutrition, vol. 58, no. 3, pp. 474-480, 2004.

[29] M. M. A. Abulmeaty, A. M. Almajwal, and H. M. Z. Hassan, "New cutoff values for fat mass index, fat-free mass index and percent body fat in overweight and obese men living in Riyadh, SA," International Journal of Diabetes in Developing Countries, vol. 36, no. 2, pp. 204-212, 2016.

[30] T. J. Cole, M. C. Bellizzi, K. M. Flegal, and W. H. Dietz, "Establishing a standard definition for child overweight and obesity worldwide: international survey," BMJ, vol. 320, no. 7244, p. 1240, 2000.

[31] A. M. Roza and H. M. Shizgal, "The Harris Benedict equation reevaluated: resting energy requirements and the body cell mass," The American Journal of Clinical Nutrition, vol. 40, no. 1, pp. 168-182, 1984.

[32] D. Frankenfield, L. Roth-Yousey, and C. Compher, "Comparison of predictive equations for resting metabolic rate in healthy nonobese and obese adults: a systematic review," Journal of the American Dietetic Association, vol. 105, no. 5, pp. 775-789, 2005.

[33] P. J. M. Weijs and G. A. A. M. Vansant, "Validity of predictive equations for resting energy expenditure in Belgian normal weight to morbid obese women," Clinical Nutrition, vol. 29, no. 3, pp. 347-351, 2010.

[34] P. J. Weijs, "Validity of predictive equations for resting energy expenditure in US and Dutch overweight and obese class I and II adults aged 18-65 y," The American Journal of Clinical Nutrition, vol. 88, no. 4, pp. 959-970, 2008.

[35] J. M. Bland and D. G. Altman, "Statistical methods for assessing agreement between two methods of clinical measurement," Lancet, vol. 327, no. 8476, pp. 307-310, 1986.

[36] M. Marra, I. Cioffi, R. Sammarco et al., "Prediction and evaluation of resting energy expenditure in a large group of 
obese outpatients," International Journal of Obesity, vol. 41, no. 5, pp. 697-705, 2017.

[37] M. Elia, "Energy expenditure in the whole body," in Energy Metabolism. Tissue Determinants and Cellular Corollaries, J. M. Kinney and H. N. Tucker, Eds., pp. 19-59, Raven Press, New York, USA, 1992.

[38] Z.-Y. Rao, X.-T. Wu, B.-M. Liang, M.-Y. Wang, and W. Hu, "Comparison of five equations for estimating resting energy expenditure in Chinese young, normal weight healthy adults," European Journal of Medical Research, vol. 17, no. 1, p. 26, 2012.

[39] E. P. De Oliveira, F. L. Orsatti, O. Teixeira, N. Maestá, and R. C. Burini, "Comparison of predictive equations for resting energy expenditure in overweight and obese adults," Journal of Obesity, vol. 2011, Article ID 534714, 5 pages, 2011.

[40] M. Siervo, V. Boschi, and C. Falconi, "Which REE prediction equation should we use in normal-weight, overweight and obese women?," Clinical Nutrition, vol. 22, no. 2, pp. 193-204, 2003.

[41] D. A. De Luis, R. Aller, O. Izaola, and E. Romero, "Prediction equation of resting energy expenditure in an adult Spanish population of obese adult population," Annals of Nutrition and Metabolism, vol. 50, no. 3, pp. 193-196, 2006.

[42] C. A. Fett, W. C. R. Fett, and J. S. Marchini, "Resting energy expenditure measured vs. estimated and this relationship with body composition in women," Arquivos Brasileiros de Endocrinologia \& Metabologia, vol. 50, no. 6, pp. 1050-1058, 2006.

[43] V. Wahrlich and L. A. Anjos, "Validation of predictive equations of basal metabolic rate of women living in Southern," Revista de Saúde Pública, vol. 35, no. 1, pp. 39-45, 2001. 


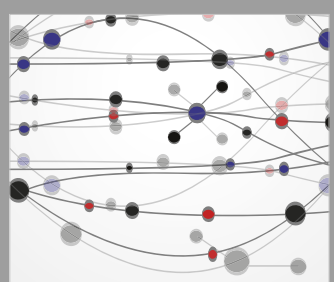

The Scientific World Journal
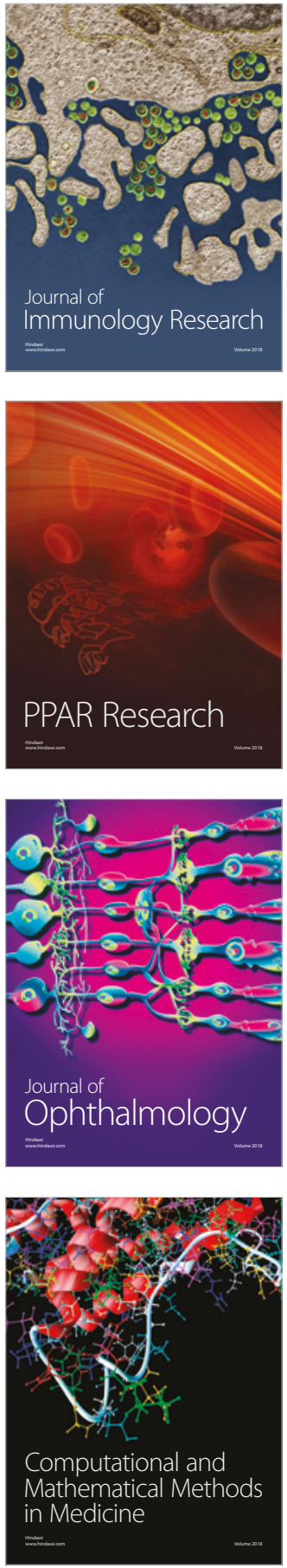

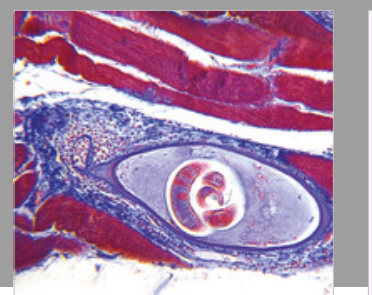

Gastroenterology Research and Practice

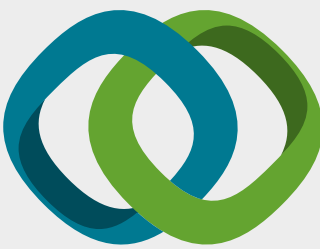

\section{Hindawi}

Submit your manuscripts at

www.hindawi.com
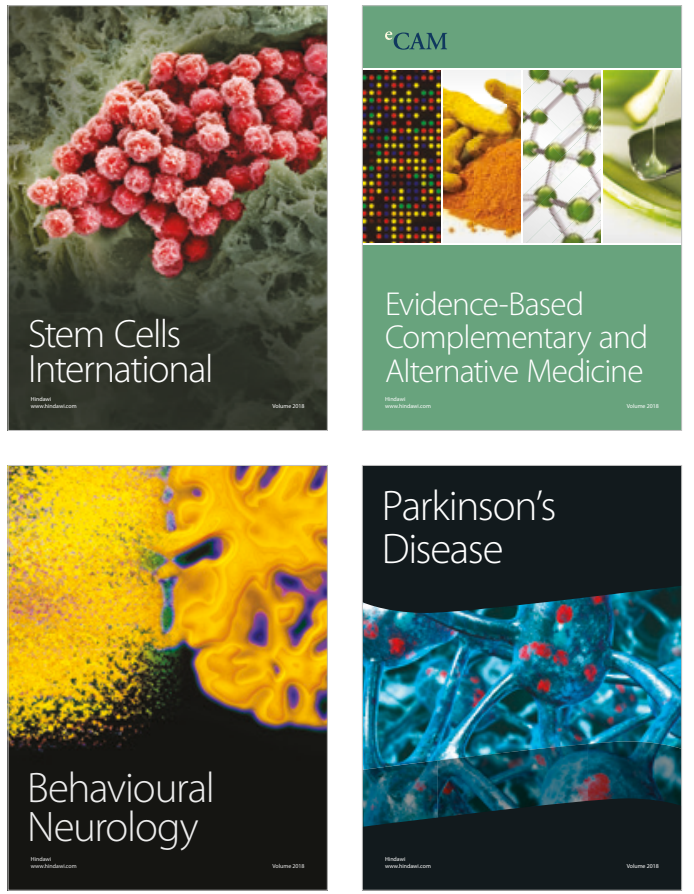

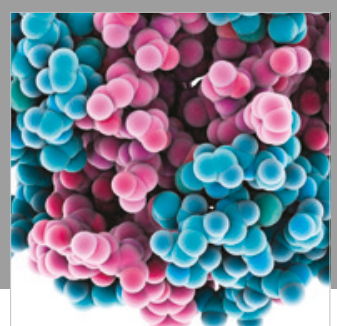

ournal of

Diabetes Research

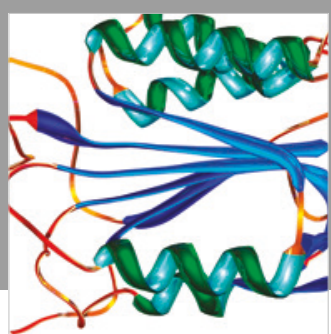

Disease Markers
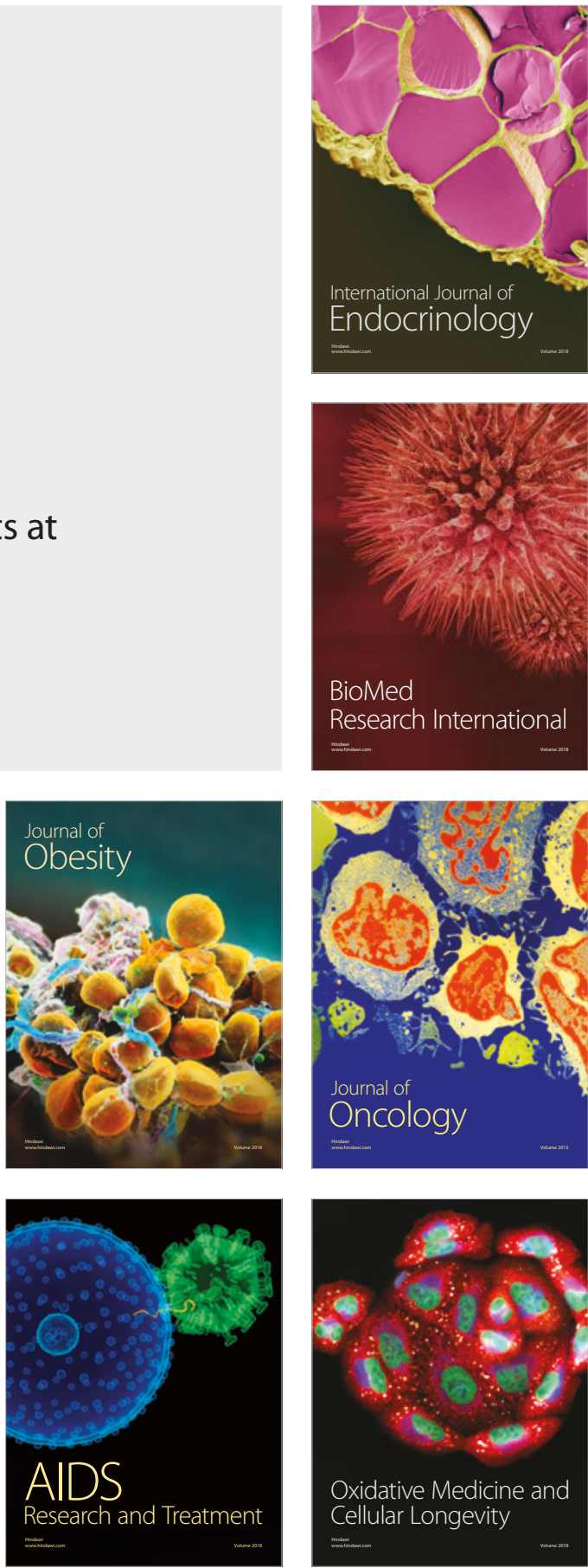